\title{
Paliperidone extended-release: does it have a place in antipsychotic therapy?
}

\author{
This article was published in the following Dove Press journal: \\ Drug Design, Development and Therapy \\ 10 March 201I \\ Number of times this article has been viewed
}

\section{Maximilian Gahrı,* \\ Markus A Kölle ${ }^{\text {,* }}$ \\ Carlos Schönfeldt-Lecuona' \\ Peter Lepping ${ }^{2}$ \\ Roland W Freudenmann' \\ 'Department of Psychiatry and Psychotherapy, University of UIm, Ulm, Germany; ${ }^{2}$ Department of Psychiatry, Glyndŵr University, Wales, UK}

*Both authors contributed equally and their order was determined by coin toss.
Correspondence: Maximilian Gahr Department of Psychiatry and Psychotherapy, University of Ulm, Leimgrubenweg 12-14, 89075 Ulm, Germany

Tel +49073 I 5006141 I

Fax +490 73I 50061402

Email maximilian.gahr@uni-ulm.de
Abstract: Paliperidone (9-hydroxy-risperidone), the active metabolite of risperidone, was approved for treating schizophrenia worldwide in 2006 as paliperidone extended-release (PER), and became the first second-generation antipsychotic specifically licensed for treating schizoaffective disorder in 2009. However, at the same time, its comparatively high cost gave rise to concerns about the cost-effectiveness of PER as compared with its precursor, risperidone. This paper reviews the existing knowledge of the pharmacology, kinetics, efficacy, tolerability, and fields of application of PER, and compares PER with risperidone in order to determine whether it has a place in antipsychotic therapy. An independent assessment of all relevant publications on PER published until July 2010 was undertaken. PER has a unique pharmacological profile, including single dosing, predominantly renal excretion, low drug-drug interaction risk, and differs from risperidone in terms of mode of action and pharmacokinetics. High-level evidence suggests that PER is efficacious and safe in schizophrenia, schizoaffective disorder, and acute manic episodes. There is a striking lack of published head-to-head comparisons between PER and risperidone, irrespective of indication. Low-level evidence shows a lower risk for hyperprolactinemia and higher patient satisfaction with PER than with risperidone. PER adds to the still limited arsenal of second-generation antipsychotics. In the absence of direct comparisons with risperidone, it remains difficult to come to a final verdict on the potential additional therapeutic benefits of PER which would justify its substantially higher costs as compared with risperidone. However, in terms of pharmacology, the available evidence cautiously suggests a place for PER in modern antipsychotic therapy.

Keywords: antipsychotic treatment, paliperidone, extended-release, second-generation antipsychotics, psychopharmacology, schizophrenia, bipolar disorder

\section{Background}

Paliperidone is the active metabolite of the widely used second-generation antipsychotic, risperidone, is the generic name for 9-hydroxy-risperidone. On December 20, 2006, palperidone was approved for the acute and maintenance treatment of schizophrenia by the US Food and Drug Administration, and thereafter in many countries worldwide. It is marketed as a special slow-release formulation referred to as paliperidone extended-release (PER).

In addition, on July 31, 2009, PER became the first second-generation antipsychotic licensed for the acute treatment of schizoaffective disorder in the US, either as monotherapy or as an adjunct to mood stabilizers and/or antidepressants. At present, PER is about to be licensed by the European Medicines Agency for this indication (more specifically, for the treatment of psychotic and manic symptoms in schizoaffective disorder, 
but not for depressive symptoms). A positive opinion was published by the Committee for Medicinal Products for Human Use on September 27, 2010 (www.ema.europa.eu). Despite several studies on its use in bipolar disorder, PER has not yet been licensed for treating any affective disorder. This is in contrast with its mother substance, risperidone, and many competitors (eg, olanzapine, quetiapine, aripiprazole, and ziprasidone). The indications for PER have increased from schizophrenia alone to include the wider spectrum of affective disorders, a pattern which is also found with the other second-generation antipsychotics.

However, the development of increasing indications for PER is in contrast with doubts about its cost-effectiveness, especially in relation to risperidone, and has given rise to cost-effectiveness studies in Europe (Greece, Italy) and in the US. Risperidone, first launched in 1991, is available at a much lower cost and, in terms of chemistry, differs from paliperidone only by a single hydroxyl group. In view of the ongoing debate about drugs that are only marginally different from their mother substances ("me-too" drugs) and the growing interest in the pharmacoeconomics of antipsychotic treatment, Citrome predicted in 2007 that "... with the impending availability of oral risperidone as a generic medication, the cost of oral paliperidone will likely become a significant obstacle to its use". ${ }^{1}$

In Germany, for example, after changes were made to the funding of the public health system in 2006, PER became the first, and thus far only, second-generation antipsychotic for which only a small fixed amount of the price is subsidized by statutory health insurance funds. Because the manufacturer did not reduce the price, patients now have to pay most of the cost themselves, which is in contrast with other antipsychotics. As a consequence, PER has become disestablished for all practical purposes in Germany for the time being, despite no changes to its licensing or approval status.

Accordingly, we set out to gather and evaluate published data on the pharmacology, efficacy, and safety, as well as the subjective quality of life measures, associated with the use of PER. We aimed at assessing all the available evidence to answer the question of whether PER and its precursor, risperidone, are equivalent, thus determining whether there is a place for PER in antipsychotic therapy or not. Special attention was paid to characteristics that may distinguish PER from other antipsychotics, especially risperidone.

At the time of writing, we could identify 10 review articles focusing on PER ${ }^{1-10}$ with a MEDLINE search using PubMed, mainly dealing with efficacy and safety issues.
There were nine nonsystematic reviews and one systematic review. ${ }^{2}$ Declarations of interest were missing in two cases. ${ }^{3,8}$ For the other eight publications, the authors had direct affiliations with Janssen-Cilag or Johnson \& Johnson (in particular, authors received honoraria from Janssen-Cilag and conducted clinical research with the support of JanssenCilag, ${ }^{1}$ authors were employed by Johnson \& Johnson, ${ }^{4}$ one author was on the speakers' bureau for Janssen, ${ }^{5}$ the authors had received honoraria for lectures supported by Janssen-Cilag and received fees for advisory board and congress presentations, ${ }^{6}$ one author had been a consultant for Janssen-Cilag, ${ }^{2}$ one author has received research grants and speakers' honoraria from Janssen-Cilag, ${ }^{7}$ one author was employed within Janssen-Cilag, was a member of the speakers' bureau for Janssen-Cilag, and an advisor/consultant for Janssen-Cilag, with editorial support and funding from Ortho-McNeil Janssen Scientific Affairs, ${ }^{9}$ and during the peer review process the manufacturer of PER was offered an opportunity to comment on the $\operatorname{article}^{10}$ ). The authors of the present review, in contrast, do not have any conflicts of interest and are not affiliated with the manufacturer of PER or risperidone.

On July 21, 2010, we conducted a PubMed search using the search term "paliperidone" and retrieved 282 hits. In addition, we visited the www.clinicaltrials.com website to identify any further ongoing clinical trials involving PER. We also visited the US Food and Drug Administration database to obtain data regarding newly reported side effects, eg, concerning the potential of PER for abuse and physical dependence. All retrieved publications were assessed independently by two of the authors (MG, MK) for their relevance to our research questions. For this review, we only considered papers published in peer-reviewed journals. Accordingly, 64 papers were selected and the relevant information was extracted. Notably, almost all of the published papers that presented original data originated from only 11 clinical studies.

In this paper, we briefly review current issues in the antipsychotic treatment of both the schizophrenia spectrum and the affective disorders. This includes comparisons of efficacy and tolerability of the first-generation and secondgeneration antipsychotics, and discussion of the emerging clinical problems associated with antipsychotic therapy, including adherence to therapy and the metabolic risks associated with some antipsychotics. We then summarize all available data on PER and assess its place amongst the second-generation antipsychotics. 


\section{Current issues in treating schizophrenia and bipolar disorder}

According to the World Health Organization (WHO), severe and enduring mental illnesses, such as depression, schizophrenia, and bipolar affective disorder, are major causes of disability worldwide. ${ }^{11}$ In fact, all three rank amongst the top 10 on the WHO list of illnesses that cause disability. Schizophrenia, bipolar affective disorder, and, to a lesser degree, depression, are treated with antipsychotic medication. However, despite significant progress in pharmacotherapy with antipsychotics, many problems remain unresolved.

A significant problem with antipsychotics is their side effect profile. First-generation antipsychotics, such as haloperidol or perphenazine, have traditionally been associated with extrapyramidal side effects (including irreversible tardive dyskinesia), hyperprolactinemia and its consequences, sedation, and vegetative as well as orthostatic symptoms to various degrees. Since 1991, with the development of risperidone, the so-called second-generation antipsychotics have been marketed as being more effective, having fewer side effects, and as being potentially neuroprotective, leading to calls for their early use in patients with schizophrenia. In reality, they have different but equally significant side effects, including metabolic syndrome, weight gain, and QTc prolongation, depending on the single substance involved. This limits their use to a similar degree, just as the side effects of the first-generation antipsychotics limit their use. Furthermore, our aging population increases the need to consider cardiovascular problems that may arise as side effects of these medications. A systematic review has also shown that it remains unclear whether antipsychotics increase or reduce cell stress, and claims of neuroprotective properties of antipsychotics seem premature. ${ }^{12}$ Furthermore, there is the issue of tardive dyskinesia, which has caused significant problems for psychiatric patients in the past. Whilst this is much more likely to occur with first-generation antipsychotics, it can also occur with the second-generation agents.

After almost a decade of international opinion that advocated the first-line use and superior efficacy of secondgeneration antipsychotics, the US Clinical Antipsychotic Trials of Intervention Effectiveness study, with its innovative endpoint, "time to discontinuation for any cause", was the first to indicate that the second-generation antipsychotics as a group are not superior to the older drug, perphenazine. ${ }^{13}$ Olanzapine was shown to be superior to the other tested second-generation antipsychotics in terms of time to discontinuation, but was more prone than its competitors to cause metabolic side effects.
In the UK, CUTLASS1 (Cost Utility of the Latest Antipsychotic Drugs in Schizophrenia Study) found that first-generation antipsychotics (largely sulpiride) and second-generation antipsychotics (olanzapine, risperidone, amisulpride, quetiapine) did not differ in overall efficacy as measured by the Positive and Negative Syndrome Scale (PANSS), extrapyramidal side effects, quality of life, and even patient preference over a period of 52 weeks. ${ }^{14} \mathrm{~A}$ nonsignificant trend of lower direct and indirect costs was reported in the first-generation antipsychotic arm.

An influential meta-analysis by Leucht et al ${ }^{15}$ compared nine second-generation antipsychotics (including risperidone but not paliperidone) with a number of first-generation antipsychotics (mainly haloperidol) in terms of efficacy and tolerability. With regard to efficacy, the authors found only four second-generation antipsychotics (clozapine, olanzapine, amisulpride, risperidone) to be superior to first-generation antipsychotics in overall efficacy, whilst others, such as aripiprazole, quetiapine, and ziprasidone, were not. ${ }^{15} \mathrm{~A}$ similar pattern was also seen in the treatment of negative symptoms. This supports the idea that second-generation antipsychotics are not a homogenous group, and cannot be defined by their specific effects on negative symptoms or any other specific features. In terms of tolerability, Leucht et al showed that all second-generation antipsychotics caused significantly fewer extrapyramidal side effects than did haloperidol, but this effect diminished when they were compared with lowpotency first-generation antipsychotics. These investigators also showed that all the second-generation antipsychotics, with the exception of ziprasidone and aripiprazole, caused more weight gain than haloperidol, to varying degrees, but not more than is seen with the low-potency first-generation antipsychotics. A similar risk pattern of metabolic side effects with the second-generation antipsychotics was reported by a follow-up study from the same research group. ${ }^{15}$ In terms of extrapyramidal side effects, it seems that the superiority of second-generation antipsychotics in this regard reduces significantly when low-potency first-generation antipsychotics with a low incidence of extrapyramidal symptoms are used, and when their dosing is appropriately low. However, there is no doubt that, by and large, second-generation antipsychotics as a group produce less tardive dyskinesia, although the difference appears less pronounced than previously thought. ${ }^{16}$ Lepping et al showed improvements of limited clinical relevance for all antipsychotics, with the exception of amisulpride and olanzapine, which appeared most clinically relevant, being the only antipsychotics that 
achieved Clinical Global Impression-Severity (CGI-C) score improvements in the moderate range. In keeping with other meta-analyses, their results showed that aripiprazole, quetiapine, sertindole, and ziprasidone showed smaller CGI-C score improvements than haloperidol (using PANSS and/ or Brief Psychiatric Rating Scale [BPRS] score translation into CGI-C scores). ${ }^{17}$

Important obstacles in the effective treatment of schizophrenia include nonadherence, which is at least in part due to patients' lack of insight. This has increased the necessity for drugs that can be taken once daily, ie, those having a long elimination half-life. Depot antipsychotics are the most common way of improving adherence to treatment, even in first-episode schizophrenia. ${ }^{18}$ However, Hamann et al recently found that most psychiatrists have to judge depot medication as superior with respect to relapse prevention before they recommend it to patients. ${ }^{19}$ This clearly leaves room for more long-acting oral antipsychotic compounds.

Polypharmacy is commonplace in the treatment of psychiatric patients. ${ }^{20}$ Whilst this is partially due to the many comorbidities that patients with schizophrenia suffer from, and may even be beneficial in some cases, ${ }^{21}$ polypharmacy highlights the need for psychotropic medication to be as little prone to drug-drug interactions as possible, especially in aging and multimorbid populations.

In summary, there is an increasing understanding that second-generation antipsychotics are diverse and should not be seen as a homogenous group. Their efficacy, as well as their side effect profile, is variable. In relation to first-generation antipsychotics, each second-generation antipsychotic needs to be seen on its own merits. A number of credible studies and meta-analyses have suggested that clozapine is the most efficacious antipsychotic, followed by a group consisting of amisulpride, olanzapine, and risperidone, and that these four agents are more effective than the various first-generation and other second-generation antipsychotics. The second-generation antipsychotics have very different risks of sedation, weight gain, hyperprolactinemia, QTc prolongation, and extrapyramidal side effects. The desirable attributes for any antipsychotic are ease to administration, a long half-life with few drug interactions, minimal side effects and improved adherence, and availability at a cost that is justifiable in the context of increasingly reduced health care resources. Notably, PER, in contrast with risperidone, was not part of any of these seminal studies on the use of antipsychotics.

Antipsychotics have also increasingly been used in the treatment of bipolar affective disorder, where it is being suggested that antipsychotics may be useful as mood stabilizers in the treatment of acute mania as well as in maintenance therapy. However, most studies have been short, and their results need to be replicated in larger studies with varying outcome measures, to avoid the misinterpretations that occurred with the schizophrenia studies involving the second-generation antipsychotics. Very recently, quetiapine became the first second-generation antipsychotic to be licensed as an add-on in treating depression. Altogether, second-generation antipsychotics are increasingly expanding their scope and licensed indications from schizophrenia into the affective disorder spectrum.

\section{Pharmacological properties Pharmacodynamics}

A monoaminergic antagonist belonging to the chemical class of benzoxisoxazole derivatives, paliperidone is a centrally acting dopamine $\mathrm{D}_{2}$ - and serotonin $5-\mathrm{HT}_{2 \mathrm{~A}}$ receptor antagonist with predominantly $5 \mathrm{HT}_{2 \mathrm{~A}}$ antagonist activity. ${ }^{22}$ Additionally, it is an antagonist at alpha $\mathrm{A}_{1}$ - and alpha ${ }_{2}$-adrenergic receptors and $\mathrm{H}_{1}$-histaminergic receptors, which may explain weight gain, orthostatic hypotension, and sedative side effects. Paliperidone has no affinity with cholinergic muscarinic receptors, predicting a low risk of anticholinergic side effects, including cognitive dysfunction and constipation, and also has no significant action at beta $_{1}$ - and beta $_{2}$-adrenergic receptors. ${ }^{22}$ Like risperidone, its mother substance, paliperidone is a potent dopamine $\mathrm{D}_{2}$ antagonist. The $\mathrm{K}_{\mathrm{i}}$ values for binding to $\mathrm{D}_{2}$ versus $5-\mathrm{HT}_{2 \mathrm{~A}}$ receptors for risperidone and paliperidone are 5.9 and $4.8 \mathrm{nM}$ versus 0.16 and $0.25 \mathrm{nM}$, respectively. ${ }^{23}$ The off-rate for dissociation from human cloned $\mathrm{D}_{2}$ receptors in tissue culture cells is faster for paliperidone (60 seconds) than for risperidone (27 minutes). ${ }^{23}$ Karlsson et al investigated the receptor occupancy of a single dose of two different formulations of paliperidone, an intermediate-release formulation of paliperidone $1 \mathrm{mg}$, and an extended-release formulation (PER $6 \mathrm{mg}$ ) in three and four healthy subjects, respectively. ${ }^{22}$ With positron emission tomography measurements, $\mathrm{D}_{2}$ and $5 \mathrm{HT}_{2 \mathrm{~A}}$ receptor occupancy was calculated with two radioligands before administering paliperidone and at around the time of the predicted peak plasma concentration. Whereas a single dose of paliperidone intermediate-release corresponded to a median $\mathrm{D}_{2}$ receptor occupancy of $48 \%$ at 2.5 hours postdose and a median $5 \mathrm{HT}_{2 \mathrm{~A}}$ receptor occupancy of $65 \%$ at 4.5 hours postdose, a single dose of PER $6 \mathrm{mg}$ corresponded to a median $\mathrm{D}_{2}$ receptor occupancy of $64 \%$ at 22 hours postdose (peak plasma concentration), and this 
decreased to a median of $53 \%$ at 46 hours postdose. These findings suggest that the estimated effective dose of PER ( $>60 \% \mathrm{D}_{2}$ receptor occupancy) is more than $3 \mathrm{mg}$ per day. Brain imaging studies have consistently predicted that PER 6-9 mg daily induces striatal $\mathrm{D}_{2}$ receptor occupancy rates of $70 \%-80 \%,{ }^{24}$ and suggest therapeutic efficacy of antipsychotic drugs when a $\mathrm{D}_{2}$-receptor occupancy greater than $65 \%$ is reached in the basal ganglia, ${ }^{25}$ whereas an increased incidence of extrapyramidal symptoms occurs when occupancy exceeds $80 \%-85 \%{ }^{25}$ Due to looser binding to $\mathrm{D}_{2}$ receptors and lower fluctuations of levels in plasma, ${ }^{26} \mathrm{PER}$ is theoretically associated with a lower risk of extrapyramidal side effects than risperidone. ${ }^{23}$ Therefore, PER can be seen as having different pharmacodynamic properties and a different neural mechanism of action to risperidone.

\section{Pharmacokinetics}

Paliperidone has been introduced and approved worldwide in a formulation that uses the so-called osmotically controlled release oral delivery system (OROSC), ALZA Corporation, Mountain View, CA). Paliperidone itself and paliperidone intermediate-release have been tested, but have not been approved. The OROS technology has been studied and refined over the past 30 years. It has been used for a number of commonly used medications, including nifedipine, verapamil, doxazosin, oxybutynin, and methylphenidate. ${ }^{27}$ The system allows for continuous delivery of the pharmacologically active drug over a 24-hour period, ${ }^{27,28}$ and consists of an osmotically active trilayer, containing two drug layers and a push compartment, surrounded by a semipermeable membrane. After ingestion, the overcoat erodes in the gastrointestinal tract and water passes through the semipermeable membrane. The water interacts with the hydrophilic polymers of the core which, in turn, swells and forms a gel, thereby pushing paliperidone outwards through a delivery orifice. Because the passage of water through the membrane is at a fixed rate, it controls the rate of drug release from the system into the lumen of the intestinal tract. ${ }^{27,29}$ The OROS principle avoids peak-to-trough variations in plasma concentrations, ${ }^{6,27}$ with only minimal fluctuations in plasma drug levels. ${ }^{28}$ After a single $12 \mathrm{mg}$ dose of PER, the peak-to-trough fluctuation is only $38 \%$, which is in contrast with a fluctuation of $125 \%$ seen after a single $4 \mathrm{mg}$ dose of risperidone..$^{30}$ In the dosage range of 3-15 mg once daily, the overall pharmacokinetic profile of PER is dose-dependent. ${ }^{28,31}$ Maximum plasma concentrations are reached 24 hours after administering a single oral dose, and steady-state plasma levels are achieved after four daily doses. ${ }^{28}$ The absolute bioavailability of PER is approximately $28 \% .{ }^{32}$ According to the manufacturer's product information, a single dose of PER $12 \mathrm{mg}$ administered with food is associated with a $60 \%$ increase in the maximum plasma concentration and a 54\% increase in the area under the plasma concentration-time curve compared with administration in the fasting state in ambulatory individuals. However, the underlying mechanisms are unclear, because PER was administered without regard to food intake in clinical trials. ${ }^{33,34}$ Despite that, it has been suggested that PER may be administered without regard to meals. ${ }^{33,34}$ Finally, the tablet has to be swallowed whole and must not be chewed, split, or crushed. ${ }^{34}$ When administering the drug, patients should be informed by the treating physician that the shell of the tablet is nonabsorbable and thus will be excreted in their feces. This is particularly important in patients suffering from paranoid or psychotic symptoms who might interpret the excretion of a foreign object in a delusional manner.

As already mentioned, paliperidone is the active metabolite of risperidone, and is thus generated after oral administration of risperidone by CYD2D6-related hydroxylation of risperidone. Paliperidone is minimally metabolized in the liver by the cytochrome P450 (CYP) enzyme system and, therefore, has a low potential for causing drug-drug interactions. ${ }^{35}$ The only two CYP isoenzymes identified to break down paliperidone to some extent are CYP 3A4 and $2 \mathrm{D} 6 .^{34}$

Although there are no human data regarding the influence of PER on $\mathrm{P}$ glycoprotein, a study by Zhu et $\mathrm{al}^{36}$ demonstrated that risperidone and, to a lesser extent, paliperidone intermediate-release, have the potential to inhibit $\mathrm{P}$ glycoprotein-mediated transport. Thus, the pharmacokinetics, and hence the pharmacodynamics, of coadministered drugs can be influenced via this mechanism. Studies in healthy subjects have revealed no clinically relevant effects of paroxetine on the pharmacokinetics of PER. ${ }^{37}$ Population pharmacokinetic analyses also suggest that paliperidone exposure and clearance do not differ between extensive or poor metabolizers of CYP 2D6 substrates. ${ }^{33}$ Four primary metabolic pathways (each accounting for $\leq 10 \%$ of the oral dose) were identified, ie, dealkylation, hydroxylation, dehydrogenation, and benzisoxazole scission. ${ }^{34,38}$ Although hepatic metabolism is present to some degree, renal excretion seems to be the primary route of elimination for paliperidone, with $59 \%$ of the oral dose excreted unchanged in the urine. ${ }^{38}$ About half of the renal excretion occurs by active secretion. ${ }^{38}$ In spite of hepatic metabolism, the impact of moderate hepatic impairment on paliperidone pharmacokinetics is not considered clinically 
relevant, so dosage adjustments in patients with mild to moderate hepatic impairment are not required..$^{34,39}$ The impact of renal impairment on plasma and urine pharmacokinetics of orally administered PER $3 \mathrm{mg}$ was assessed in subjects with varying degrees of renal impairment versus subjects with normal renal function. ${ }^{40}$ The total paliperidone clearance decreased with increasing degrees of renal impairment, and was approximately $71 \%$ lower in subjects with severe renal impairment compared with healthy subjects. According to the manufacturer's prescribing information for patients with mild renal impairment (creatinine clearance $50-80 \mathrm{~mL} / \mathrm{min}$ ), the maximum recommended dose is $6 \mathrm{mg}$ /day, whereas for patients with moderate-to-severe renal impairment (creatinine clearance 10-50 $\mathrm{mL} / \mathrm{min}$ ), the maximum recommended dose is $3 \mathrm{mg} /$ day. ${ }^{34}$ An open-label, two-period, randomized, crossover study in 30 healthy males found that trimethoprim, a potent organic cation transport inhibitor, did not influence the pharmacokinetics of PER, which is an organic cation at physiological $\mathrm{pH}^{41}$ Therefore, no clinically important drug interactions are expected when PER is administered with organic cation transport inhibitors. ${ }^{41}$ Furthermore, the pharmacokinetics of PER are not significantly affected by age. ${ }^{42}$ During the absorption phase after a single dose, PER concentrations are similar between elderly and young adults. No dose adjustment of PER is required in elderly patients, unless they have renal impairment. Paliperidone is a racemic mixture of $(+)$ - and (-)- enantiomers. In vitro, there is no qualitative or quantitative difference in the pharmacological activities of these enantiomers. ${ }^{33,43}$ In summary, PER differs from risperidone in terms of two important pharmacokinetic properties, ie, a low extent of enzymatic metabolism and reduced plasma level fluctuations.

\section{Efficacy studies}

Based on the data of three pivotal clinical studies that investigated the efficacy of PER in patients with schizophrenia, pooled analyses have been done to investigate its efficacy in acute-phase and long-term treatment, in recently diagnosed schizophrenia, for negative symptoms of schizophrenia, for prominent affective symptoms in schizophrenia, and in patients previously treated with risperidone.

More recent clinical studies have been conducted to evaluate the efficacy of PER in elderly patients, and for prevention of symptom recurrence, schizophreniarelated insomnia, schizoaffective disorder, acute mania, and mixed episodes of bipolar I disorder. Finally, there is only one clinical head-to-head study that compared PER with quetiapine. Table 1 summarizes the findings of these studies.

\section{Patients with schizophrenia}

Until the search date for the present review, there were three published studies that examined the efficacy of PER. ${ }^{44-46}$ These studies had a six-week, double-blind, randomized, fixed-dose, placebo-controlled or active-controlled (olanzapine $10 \mathrm{mg}$ per day), and parallel-group design. The mean total change in the PANSS ${ }^{47,48}$ was the primary outcome measure. The PANSS is a 30 -item, widely used, validated scale quantifying key clinical features of schizophrenia in five domains (positive symptoms, negative symptoms, disorganized thought, uncontrolled hostility/excitement, and anxiety/depression). The scale scoring for each item ranges from 1 (absence of symptoms) to 7 (most severe symptoms). Generally, a score of 70-120 equates to the moderate-to-severe illness range. PANSS is a useful tool, in that a $20 \%-30 \%$ change in the total PANSS from baseline represents a clinically meaningful improvement in overall illness severity. PANSS factor scores, ${ }^{48}$ response rates (patients with $\geq 30 \%$ reduction in PANSS total score at endpoint), CGI-Severity (CGI-S) $\operatorname{scores}^{49}$ and Personal and Social Performance (PSP) ${ }^{50,51}$ scores were the secondary outcome measures. The latter scale measures personal and social functioning on a 100-point scale in 10-point increments (ie, scores of 1-10 represent lack of autonomy in basic functioning, and scores of 91-100 represent excellent functioning). It accounts for four domains of behavior, ie, socially useful activities, relationships, self care, and disturbing and/or aggressive behavior. A clinically meaningful change is reflected by improvement in one category (ie, 10 points). ${ }^{51}$

All three studies had the same design, starting with a one-week screening phase followed by a six-week doubleblind phase (with fixed doses of PER, olanzapine $10 \mathrm{mg} /$ day, or placebo). Emsley et $\mathrm{al}^{52}$ conducted a continuation study in patients who had either completed one of the six-week, double-blind studies or had terminated more than 21 days into the study because of lack of efficacy with a 52-week, openlabel, extension phase (with flexible doses of PER resulting in classification of three treatment groups with regard to the sequence of administered agents, ie, placebo/PER, PER/PER, and olanzapine/PER).

In the first study, Marder et al randomized 444 subjects with chronic schizophrenia and current acute exacerbation (PANSS score range 70-120; mean \pm standard deviation [SD] baseline score $94 \pm 12$ ) to three treatment arms, ie, PER 
Table I Paliperidone efficacy studies

\begin{tabular}{|c|c|c|}
\hline Study & Methods & Results \\
\hline \multicolumn{3}{|c|}{ Efficacy in schizophrenia } \\
\hline \multirow[t]{5}{*}{ Kane et $\mathrm{al}^{45}$} & $\mathrm{n}=628$ & Any dosage was effective \\
\hline & 6 weeks, multicenter, randomized, DB & Significant improvement PANSS \\
\hline & Placebo-controlled active-controlled & Significant improvement PANSS Marder factor scores \\
\hline & Dosage 6, 9, and $12 \mathrm{mg}$ & Significant improvement PSP \\
\hline & Active control, olanzapine $10 \mathrm{mg}$ & \\
\hline \multirow[t]{5}{*}{ Marder et $\mathrm{al}^{46}$} & $\mathrm{n}=444$ & Significant improvement PANSS \\
\hline & 6 weeks, multicenter, randomized, DB, & Significant improvement PSP: $6 \mathrm{mg}$ \\
\hline & Placebo-controlled active-controlled & \\
\hline & Dosage 6 and $12 \mathrm{mg}$ & \\
\hline & Active control olanzapine $10 \mathrm{mg}$ & \\
\hline \multirow[t]{5}{*}{ Davidson et $\mathrm{al}^{44}$} & $\mathrm{n}=618$ & Any dosage was effective \\
\hline & Dosage $3,9,15 \mathrm{mg}$ & Significant improvement in PANSS \\
\hline & Active control olanzapine $10 \mathrm{mg}$ & Significant improvement in PSP \\
\hline & & Special about this study: rapid onset of action \\
\hline & & Significant improvement on day 4 \\
\hline \multicolumn{3}{|c|}{ Efficacy in prevention of symptom recurrence in patients with schizophrenia } \\
\hline \multirow[t]{9}{*}{ Kramer et al ${ }^{61}$} & $\mathrm{n}=628$ & Symptom recession within 6 weeks: $25 \%$ with PER, \\
\hline & 6 weeks, multicenter, randomized, DB & $53 \%$ with placebo. \\
\hline & Dosage $3,6,9,12,15 \mathrm{mg}$ & Special about this study: Efficacy was measured \\
\hline & & by rate of symptom recurrence under stable \\
\hline & & medication with PER \\
\hline & 5 phases & \\
\hline & 8 weeks running: minimum 2 weeks, discharge & \\
\hline & 6 weeks & \\
\hline & Fixed dose, DB & \\
\hline \multicolumn{3}{|c|}{ Efficacy in schizophrenia compared with quetiapine } \\
\hline \multirow[t]{2}{*}{ Canuso et al ${ }^{64}$} & 6 weeks, DB, randomized, placebo-controlled. & $\begin{array}{l}\text { Significant improvement PANSS after } 2 \text { weeks: } \\
\text { only with PER }\end{array}$ \\
\hline & 2 weeks monotherapy, 4 weeks add-on therapy & $\begin{array}{l}\text { Significant improvement PANSS after } 6 \text { weeks } \\
\text { with PER, } \\
\text { Significantly greater improvement compared } \\
\text { with quetiapine }\end{array}$ \\
\hline \multicolumn{3}{|c|}{ Efficacy in elderly patients with schizophrenia } \\
\hline Tzimos et al ${ }^{59}$ & $\begin{array}{l}\mathrm{n}=1 \mathrm{I} 4 \text {, } \\
\text { Randomized, flexible dosing, placebo-controlled } \\
6 \text { weeks, DB, } 24 \text { weeks, open-label, } \\
\text { mean modal dose } 8.3 \mathrm{mg} / \text { day }\end{array}$ & Significant improvement PANSS \\
\hline \multicolumn{3}{|c|}{ Efficacy in schizophrenia-related insomnia } \\
\hline Luthringer et al ${ }^{62}$ & $\begin{array}{l}\mathrm{n}=42 \\
3 \text { weeks, randomized, DB, placebo-controlled } \\
\text { fixed dose } 9 \mathrm{mg}\end{array}$ & $\begin{array}{l}\text { Significant improvement in sleep latency, sleep onset } \\
\text { latency, number of awakenings, time awake in bed, } \\
\text { stage II sleep duration, total sleep duration, } \\
\text { sleep period time, Stage } 2 \text { sleep duration, } \\
\text { REM sleep duration }\end{array}$ \\
\hline \multicolumn{3}{|c|}{ Efficacy in schizoaffective disorder } \\
\hline Canuso et $\mathrm{al}^{57}$ & $\mathrm{n}=316$ & Significant improvement PANSS at $12 \mathrm{mg}$ \\
\hline & $\begin{array}{l}6 \text { weeks, randomized, DB, multicenter, } \\
\text { placebo-controlled } \\
\text { dose (flexible): } 6-12 \mathrm{mg}\end{array}$ & Significant improvement YMRS/HAM-D \\
\hline \multicolumn{3}{|c|}{ Efficacy in bipolar disorder (manic episode) } \\
\hline \multirow[t]{2}{*}{ Berwaerts et $a^{66}$} & $n=469$ & Significant improvement YMRS at $12 \mathrm{mg}$ only \\
\hline & $\begin{array}{l}3 \text { weeks, randomized, DB, placebo-controlled. } \\
\text { fixed dose: } 3,6,12 \mathrm{mg}\end{array}$ & \\
\hline
\end{tabular}


Table I (Continued)

\begin{tabular}{|c|c|c|}
\hline Study & Methods & Results \\
\hline \multicolumn{3}{|c|}{ Efficacy in bipolar disorder (manic and mixed episode) } \\
\hline Vieta et $\mathrm{al}^{68}$ & $\begin{array}{l}\mathrm{n}=493 \\
\text { Placebo-controlled, active-controlled, } \\
\text { fixed dose, 3, 6, 9, } 12 \mathrm{mg} \text {, } \\
\text { Active control: quetiapine } 400-800 \mathrm{mg} \\
\text { followed by } 9 \text { weeks, multicenter, randomized, } \\
\text { DB, placebo-controlled } \\
\text { dosages 3, 6, 9, } 12 \mathrm{mg} \\
\text { Active control: quetiapine } 400-800 \mathrm{mg}\end{array}$ & $\begin{array}{l}\text { Significant improvement YMRS, no significant } \\
\text { difference between quetiapine and PER in } \\
\text { treatment effect, response rate, } \\
\text { remission rate }\end{array}$ \\
\hline \multicolumn{3}{|c|}{ Long-term efficacy of PER in treatment of acute schizophrenia } \\
\hline Emsley et $\mathrm{al}^{52}$ & $\begin{array}{l}\mathrm{n}=1083 \\
52 \text { weeks, open-label extension of the three } \\
\text { pivotal six-week studies } \\
\text { flexible dose: } 3-15 \mathrm{mg}\end{array}$ & $\begin{array}{l}\text { Maintenance of improvements of PANSS, PSP and } \\
\text { CGI-S of the three six-week double-blind studies } \\
\text { PER can maintain improvements in symptoms and } \\
\text { personal and social functioning. }\end{array}$ \\
\hline
\end{tabular}

Abbreviations: PER, paliperidone extended release; $n$, number of subjects; DB, double-blind; PANSS, positive and negative symptom scale in schizophrenia; PSP, Personal and Social Performance scale; YMRS, Young Mania Rating Scale; HAM-D, Hamilton Depression Score; CGI-S, Clinical Global Impression-Scale.

$6 \mathrm{mg}$ or $12 \mathrm{mg}$ fixed doses, placebo, and olanzapine $10 \mathrm{mg}$ per day. ${ }^{46}$ Of the 444 patients screened and randomized, 432 patients were included in the intention-to-treat group. Demographic and baseline characteristics of the 432 intention-to-treat patients were similar across all groups. Only 192 patients (43\%) of the 444 patients randomized completed the study. The olanzapine arm was an active control group to confirm assay sensitivity and was not included in the statistical models for efficacy analyses, thus missing the opportunity for a useful head-to-head analysis. With both doses of PER, there was a statistically significant difference in PANSS total score in comparison with placebo (6 $\mathrm{mg}$ dose, $P=0.006 ; 12 \mathrm{mg}$ dose, $P<0.001)$. In the $6 \mathrm{mg}$ group, there was also a statistically significant difference from placebo at every postbaseline rating from day 4 onwards $(P<0.05)$, and in the $12 \mathrm{mg}$ group from day 15 onwards $(P<0.05)$. Clinical response rates (defined by $\geq 30 \%$ improvement from the baseline PANSS total score) were also statistically significantly higher in the PER groups than in the placebo group (6 mg 50\% $[P<0.03]$; $12 \mathrm{mg} 51 \%[P=0.012]$; placebo $34 \%$ ). Olanzapine $10 \mathrm{mg}$ per day yielded a response rate of $46 \%$. The rate of patients classified as "marked/severely ill/ extremely severe" on the CGI-S scale decreased in both the PER arms and in the active control group when comparing baseline and the most recent observation. This decrease was more pronounced than in the placebo arm (6 mg PER 57.6\% to $26.1 \%$; $12 \mathrm{mg}$ PER $64.0 \%$ to $20.7 \%$; placebo $60 \%$ to $44.7 \%$; olanzapine $70.5 \%$ to $29.6 \%$ ). PSP scores improved in both PER dose groups, but only the $6 \mathrm{mg}$ dose group achieved a statistically significant change in comparison with the placebo group $(P=0.007)$.
Kane et al performed a similar prospective, randomized, placebo-controlled study ${ }^{45}$ that used three PER doses instead of only two, ie, 6, 9, and $12 \mathrm{mg}$ daily. Six hundred and thirty patients were recruited, and 415 (66\%) completed the study. Demographic and baseline characteristics were matched across the five treatment arms. All three doses of PER achieved a significantly stronger decrease in mean PANSS total score $(P<0.001)$ and in all five Marder factor scores from baseline to endpoint $(P<0.001)$. For PER $12 \mathrm{mg}$, the mean total PANSS score changes were significantly greater than with placebo starting from day $4(P<0.01)$, and for the $6 \mathrm{mg}$ and $9 \mathrm{mg}$ doses from day 8 onwards $(P<0.05)$. Response rates $(\geq 30 \%$ decrease in PANSS total score) were nearly doubled in the PER groups (6 mg, 56\%; $9 \mathrm{mg}, 51 \%$; $12 \mathrm{mg}, 61 \%$ ) as compared with placebo $(30 \%, P<0.001)$, while the response rate with the active control, olanzapine $10 \mathrm{mg}$ per day, was similar (52\%). A strikingly lower percentage of subjects in the PER group was classified as "marked/severely ill/extremely severe" on CGI-S score from baseline to endpoint $(6 \mathrm{mg}$ PER, 63\% to $21 \%$; $9 \mathrm{mg}$ PER, $57 \%$ to $23 \% ; 12 \mathrm{mg}$ PER, $64 \%$ to $16 \%$ ) in comparison with the placebo $(60 \%$ to $51 \%$ ). In the olanzapine $10 \mathrm{mg}$ /day group, the corresponding values were $64 \%$ at baseline and $24 \%$ at endpoint. PSP scale scores improved statistically significantly from baseline to endpoint for all three doses of PER compared with placebo $(P<0.001)$.

Using a similar study design, Davidson et $\mathrm{al}^{44}$ administered a broader dosage range of PER, ie, $3 \mathrm{mg}, 9 \mathrm{mg}$, and $15 \mathrm{mg}$. Six hundred and eighteen patients were randomized, and 365 (59\%) completed the study. Demographic and base- 
line characteristics were similar across the treatment groups. All PER doses achieved significantly greater improvements in PANSS total and Marder factor scores at endpoint versus placebo $(P<0.01)$. From day 4 , all three PER doses showed statistically significantly greater PANSS score reductions than the placebo. With all three PER doses, the clinical response at endpoint was more than twice as high as for the placebo (3 mg, 40\%; $9 \mathrm{mg}, 46 \%$; $15 \mathrm{mg}, 53 \%$; placebo, 18\%, $P=0.005)$. In comparison, the proportion of responders in the olanzapine $10 \mathrm{mg}$ /day group was $52 \%$ at endpoint. PSP scale scores from baseline to endpoint were also statistically significantly improved with all three doses of PER versus the placebo $(3 \mathrm{mg}, 8.3 \pm 17.1 ; 9 \mathrm{mg}, 7.6 \pm 14.2 ; 15 \mathrm{mg}$, $12.2 \pm 15.7$; placebo, $-1.5 \pm 15.8, P<0.001)$. Finally, markedly fewer patients in the PER groups were classified as "marked/severely ill/extremely severe" at endpoint compared with baseline on the CGI-S scale versus the placebo group (score reductions: $3 \mathrm{mg}, 54 \%$ to $32 \%$; $9 \mathrm{mg}, 52 \%$ to $23 \%$; $15 \mathrm{mg}, 57 \%$ to $17 \%$; placebo, $56 \%$ to $49 \%$ ).

\section{Post hoc analyses of the pivotal PER studies}

\section{Efficacy in acute-phase treatment}

Meltzer et al $^{53}$ analyzed the pooled data of the six-week, double-blind phases of the three aforementioned pivotal studies $^{44-46}$ to investigate the efficacy, safety, and tolerability of PER for acute-phase treatment of schizophrenia. Overall, the findings indicated clinical efficacy for all the administered doses of PER (3, 6, 9, 12, and $15 \mathrm{mg}$ ) with regard to changes in PANSS total, PANSS subscale factor, and PSP ( $P \leq 0.001)$, while the $3 \mathrm{mg}$ dose was least effective. Additionally, a statistically significantly greater proportion of PER-treated patients achieved a clinical response at all doses (defined in two ways, ie, a $\geq 30 \%$ decrease in PANSS total scores from baseline to endpoint or improvement of at least one 10-point PSP category) compared with placebo $(P \leq 0.001)$. Thus, PER $6 \mathrm{mg} /$ day was judged as the lowest effective dose for the treatment of patients with acute schizophrenia.

\section{Long-term efficacy}

Optimal control of psychotic symptoms in patients experiencing an acute exacerbation is one of the primary goals of disease management in patients with schizophrenia. To address this issue, the participants in the three international, multicenter, double-blind, and the placebo-controlled open-label six-week studies of PER ${ }^{44-46}$ were again enrolled into a 52-week open-label extension phase in which all patients received flexibly dosed $\operatorname{PER}(3,6,9,12$, and $15 \mathrm{mg} /$ day), with a starting dose of $9 \mathrm{mg} /$ day. ${ }^{52}$ The primary objective of that study was to assess the long-term efficacy, safety, and tolerability of PER 3-15 mg/day. Of 1083 patients enrolled, $507(47 \%)$ completed the 52-week, open-label extension phase. Outcome measures included PANSS, PSP, and CGI-S. During the open-label extension phase, the improvements in all efficacy measures (PANSS total score, PANSS positive and negative Marder factor, ${ }^{48}$ PSP, and CGI-S) were maintained in the active treatment groups in the six-week, doubleblind phase. Although PANSS total score improved from the open-label extension phase baseline in all groups, the most marked reduction was in the placebo/PER group, such that by 24 weeks of treatment, all groups had a similar PANSS total score. The authors concluded that PER can maintain improvements in symptoms and functioning. ${ }^{52}$

\section{Recently diagnosed schizophrenia}

In the early course of their illness, schizophrenic patients are known to be more responsive to antipsychotic treatment, prolonging remission and preventing future episodes. In this context, Canuso et al performed a post hoc analysis ${ }^{54}$ of the data of the three pivotal trials of PER ${ }^{44-46}$ and their open-label one-year extensions. ${ }^{52,53}$ The accumulated study population was divided into two groups with either recently diagnosed schizophrenia (defined as time since diagnosis up to three years) or not recently diagnosed schizophrenia (defined as time since diagnosis more than three years). In the double-blind phase, 259 patients $(21.9 \%)$ and the open-label phase 188 patients $(25.3 \%)$ were classified as recently diagnosed. Both populations improved with PER versus placebo on PANSS total score, CGI-S, and PSP at the endpoint of the double-blind phase compared with placebo (all $P<0.05$ ). Significant improvements in both populations were observed at the open-label endpoint $(P<0.0001)$, with greater improvement in the PANSS total score $(P<0.001)$ and PSP $(P<0.001)$ in the recently diagnosed population. The authors concluded that patients with recently diagnosed schizophrenia particularly benefit from PER treatment with regard to symptom reduction and functional benefit in the long term.

\section{Effects on negative symptoms of schizophrenia}

Negative symptoms of schizophrenia are known to be associated with functional disability and poor prognosis. Improvement of negative symptoms is an important goal of antipsychotic treatment. ${ }^{55}$ In this context, Turkoz et $\mathrm{al}^{56}$ investigated the direct and indirect effects of PER on negative 
symptoms in a post hoc pooled analysis of the three pivotal studies. PER treatment, compared with placebo, was associated with a significant improvement in negative symptoms, representing a $22 \%$ reduction from baseline in PANSS negative and anxiety/depression factor scores. Path analysis indicated that up to $33 \%$ of negative symptom improvement was a direct treatment effect of PER. Changes in positive symptoms and anxiety/depression symptoms mediated indirect effects on negative symptoms (51\% and $18 \%$, respectively). An inverse effect was induced by changes in movement disorders (2.1\%). All doses of PER resulted in statistically significant improvements in negative symptom scores at endpoint compared with placebo $(P<0.001)$. The authors concluded that PER has a direct effect on negative symptoms, with indirect mediation via changes in positive and depressive symptoms.

\section{Effects in schizophrenia patients with prominent affective symptoms}

In 2010, Canuso et $\mathrm{al}^{57}$ performed a post hoc analysis of the pooled data of the three six-week, multicenter, double-blind, randomized, placebo-controlled, parallel-group Phase II studies of PER. The aim of this study was to evaluate the effects of PER in patients with schizophrenia and prominent affective symptoms. Prominent affective symptoms were defined as depressive (PANSS depression item score of $\geq 5$ [moderately severe]) and/or manic (PANSS grandiosity score $\geq 4$ [moderate], plus a score of $\geq 4$ [moderate] on at last one PANSS item for excitement, hostility, uncooperativeness, or poor impulse control. Among 193 patients with prominent affective symptoms identified in the initial population, 140 (16.3\%) received PER and 53 received the placebo. PER showed statistically significant mean improvements versus the placebo in PANSS total $(P<0.001)$ and all factor scores $(P<0.01)$. Statistically significant mean improvements were observed in PSP $(P=0.004)$ and CGI-S $(P<0.001)$ scores. The authors concluded that PER was associated with statistically significant greater improvements in symptoms, functioning, and overall clinical status, as compared with the placebo in patients with schizophrenia and prominent affective symptoms.

\section{Efficacy in patients previously treated with risperidone}

Canuso et $\mathrm{al}^{58}$ performed a study based on an analysis of the pooled data of the three aforementioned clinical trials of PER ${ }^{44-46}$ to investigate whether patients with persisting active symptoms of schizophrenia when treated with risperidone benefit from switching to PER as compared with switching to placebo. Previous treatment with risperidone was defined as treatment for at least four weeks within two weeks of study entry. Mean previous daily risperidone dosage was $4.1 \mathrm{mg}$ in both switch groups, whereas the duration of previous risperidone treatment was 418.8 days in the PER switch group and 527.0 days in the placebo switch group. One hundred and ninety-eight patients met the inclusion criteria, and study completion rates were 61.3\% for PER versus $42.9 \%$ for placebo. At endpoint, PER showed statistically significant improvement versus placebo $(P<0.05)$ in PANSS, CGI-S, and PSP scores. The authors considered PER to be significantly more effective than placebo in patients who remained symptomatic with previous risperidone treatment.

\section{Efficacy in elderly patients with schizophrenia}

Tzimos et al conducted a six-week, double-blind, randomized, flexible-dose, placebo-controlled trial in 114 patients with schizophrenia at least 65 years of age. ${ }^{59}$ The mean age of patients in the study population was $69.7 \pm 4.5$ years. The assessment of safety and tolerability of flexible doses (3-12 mg/day) of PER compared with placebo was the primary aim of this study. Efficacy measures included PANSS total ${ }^{47}$ and Marder factor scores, ${ }^{48}$ CGI-S scores, ${ }^{49}$ PSP scale, ${ }^{50,51}$ and the Schizophrenia Quality of Life scale. ${ }^{60}$ Subjects were randomized 2:1 to PER $6 \mathrm{mg}$ /day or placebo. All eligible subjects were hospitalized from the first day of the double-blind phase for at least 14 days. After one week, the dose of PER was increased to $9 \mathrm{mg}$ /day, provided that $6 \mathrm{mg} /$ day had been tolerated. In the further course of the study, doses were adjusted in $3 \mathrm{mg}$ increments. Dose increases were permitted once weekly, whereas decreases could be made at any time. Relevant baseline characteristics were similar between the two treatment arms. Study completion was achieved in $84 \%$ of the PER group and $68 \%$ of placebo group. Mean modal dose of PER was $8.3 \pm \mathrm{mg} /$ day. There was a double-blind phase of six weeks followed by an open-label phase of 24 weeks, during which all patients were treated with PER. Because the study was predominantly performed to identify the safety and tolerability profile of PER in elderly patients, no formal statistical analysis was conducted, so the efficacy results must be interpreted with caution. During the double-blind phase, the PER group showed significantly greater improvement than the placebo group for PANSS factors of positive symptoms, negative symptoms, and anxiety/ depression, with a separation between treatment groups apparent from day 15 onwards. Similar PANSS scores were 
achieved by the end of the open-label phase, irrespective of the treatment received during the double-blind phase. There was no significant difference in the median change detected in the CGI-S scores between the treatment groups. Regarding results on the PSP or Schizophrenia Quality of Life scale, there were no substantial differences between the groups. The authors concluded that patients treated with PER who continued in the extension phase maintained the improvements they had gained.

\section{Prevention of symptom recurrence in patients with schizophrenia}

Subsequent to successful antipsychotic treatment of an acute exacerbation of schizophrenia, prevention of relapse becomes important. Kramer et al performed a randomized, doubleblind, placebo-controlled, parallel-group, long-term study to assess the efficacy of PER (flexible dosing of 3-15 mg/day) compared with placebo. ${ }^{61}$ The study design included five phases, ie, screening for up to five days, a run-in phase with flexible dosing for eight weeks, a stabilization phase with a fixed dose for six weeks, a double-blind phase with application of PER or placebo for variable duration, and a completion phase. The primary outcome measure was time to first recurrence in the double-blind phase, whereas recurrence was defined according to a set of predefined criteria. The secondary outcome measures were the change from baseline to endpoint on the PANSS total and CGI-S scores. Recurrence occurred in $52 \%$ of the subjects on the placebo and $25 \%$ on PER $(P=0.005)$. Postrandomization treatment with PER maintained the improvement in symptom severity achieved after the open-label phases, and mean PANSS total scores remained stable after an initial slight increase. In comparison, worsening was statistically significantly greater for patients randomized to placebo $(P<0.001)$. Discontinuation rates in the double-blind phase were higher in the PER group $(n=20,19 \%)$ compared with the placebo ( $n=8,8 \%$ ). The authors concluded that PER (flexibly dosed at $3-15 \mathrm{mg} /$ day) was superior to the placebo in preventing recurrence after stabilization.

\section{Schizophrenia-related insomnia}

Luthringer et $\mathrm{al}^{62}$ performed a randomized, double-blind, placebo-controlled, three-week study in patients $(\mathrm{n}=42)$ with schizophrenia-related insomnia. The primary outcome was the effect of PER on sleep architecture. Patients received PER $9 \mathrm{mg} /$ day or matching placebo during the 14-day double-blind phase. Polysomnograms were used to evaluate sleep architecture and sleep continuity during the 14-day double-blind phase. The effect of PER on patient-rated changes in sleep quality were assessed by daily evaluation using the Leeds Sleep Evaluation Questionnaire. ${ }^{63}$ Thirty-six patients (17 on PER and 19 on placebo) completed the study. PER treatment versus placebo resulted in clinically and statistically significant differences in sleep measurements from baseline to endpoint, including a reduction in persisting sleep latency, sleep onset latency, number of awakenings after sleep onset, time awake in bed, and stage 11 sleep duration. Prolongation in total sleep time, sleep period time, Stage 2 sleep duration, and rapid eye movement sleep duration were also observed. The results suggested that PER had a positive effect on sleep architecture, continuity, and patient-rated sleep quality, without producing or worsening daytime sleepiness.

\section{Efficacy compared with other antipsychotics in schizophrenia}

At the time of writing, there was only one published peerreviewed clinical trial dealing with the clinical efficacy of PER compared with other antipsychotics in the treatment of schizophrenia. Canuso et al conducted a randomized, doubleblind, placebo-controlled, six-week trial to investigate the efficacy of PER versus quetiapine in patients with recently exacerbated schizophrenia with two phases, ${ }^{64}$ ie, a two-week monotherapy phase followed by a four-week additive-therapy phase during which participants received additional psychotropic medications, including antipsychotics. Patients had been experiencing an acute exacerbation for less than four weeks, but more than four days. At baseline, patients were randomly assigned in a 2:2:1 ratio to treatment with PER, quetiapine, or placebo. PER was initiated at $6 \mathrm{mg}$ (days 1-3) and increased to $9 \mathrm{mg}$ on day 4 , with an optional increase to $12 \mathrm{mg}$ at day 8. Quetiapine was initiated at $50 \mathrm{mg} /$ day on day 1 , increased on day 2 to $200 \mathrm{mg} /$ day, and with subsequent daily escalation up to $600 \mathrm{mg}$ on day 5 , and an optional dose increase on day 8 to $800 \mathrm{mg} /$ day was allowed. Assessment of efficacy was by the PANSS ${ }^{47,48}$ and changes in scores on the CGI-S and CGI-C, ${ }^{49}$ and a composite response measure (a PANSS total score reduction of $\geq 30 \%$ and a CGI-C score of 1-2). A total of 399 patients were randomly assigned, and six-week completion rates were $77.5 \%$ with PER, 66.7\% with quetiapine, and $63.8 \%$ with placebo. Mean PANSS total change improvement was greater with PER than with quetiapine from day 5 through to the monotherapy endpoint compared with the placebo $(P \leq 0.001)$. Only PER showed a significantly greater PANSS improvement compared with placebo at two weeks. Patients in the PER group showed 
a greater PANSS improvement than those in the placebo group from day 5 through to the monotherapy phase endpoint $(P \leq 0.001)$, whereas quetiapine separated from placebo only at day 9. On the CGI-S and CGI-C, PER was better than both quetiapine $(P=0.002)$ and placebo $(P<0.001)$, whereas quetiapine did not separate from placebo at the two-week monotherapy. Significantly greater improvement with PER compared with quetiapine was observed at the six-week study endpoint, despite similar use of additive therapy. After six weeks, adverse event-related discontinuation rates were $6.3 \%$ for PER, 10.1\% for quetiapine, and 6.3\% for placebo groups. The authors concluded that PER, compared with quetiapine, improves symptoms earlier and to a greater degree in patients with recently exacerbated schizophrenia requiring hospitalization. Remarkably, there are no published head-to-head-comparisons of PER and risperidone.

\section{Patients with schizoaffective disorder}

Canuso et a ${ }^{65}$ carried out a randomized, double-blind, placebocontrolled, parallel-group study $(\mathrm{n}=316)$. Eligible subjects were inpatients with an acute exacerbation of schizoaffective disorder. There was a screening period, followed by randomization and double-blind treatment for six weeks. During days $2-5$ of the screening period, all other antipsychotic medication was discontinued. Subjects were randomly assigned (1:1:1) to lower doses of PER (6 mg/day, with the option to reduce to $3 \mathrm{mg} /$ day), higher doses of paliperidone (12 $\mathrm{mg} /$ day, option to reduce to $9 \mathrm{mg}$ /day), or placebo. No dosage adjustments were allowed after day 15. A total of 319 patients were randomly assigned. Changes in PANSS total scores were not statistically significantly different to the placebo $(P=0.187)$ at the lower doses of PER. Mean PANSS total score (primary outcome) improved statistically significantly with higher doses of PER compared with the placebo $(P=0.003)$.

\section{Patients with acute mania}

In a recently published study, Berwaerts et al investigated the efficacy of PER in the treatment of acute mania. ${ }^{66}$ They performed a randomized, double-blind, dose-response study $(n=469)$ and assigned subjects randomly (1:1:1:1 ratio) to one of three fixed doses of PER $(3,6$, or $12 \mathrm{mg})$, or placebo. For inclusion, subjects were required to show a Young Mania Rating Scale (YMRS) ${ }^{67}$ score of $\geq 20$. Mean change in YMRS score from baseline to the three-week endpoint (primary variable) was statistically significantly different for the PER $12 \mathrm{mg}$ group $(P<0.01)$, but not for the $6 \mathrm{mg}$ group $(P=0.30)$ or $3 \mathrm{mg}$ group $(P=0.99)$ compared with placebo. Thus, the authors concluded that PER $12 \mathrm{mg} / \mathrm{day}$ was superior to placebo in the treatment of acute mania. ${ }^{66}$ Additionally, change from baseline in YMRS total score increased with the dose of PER.

\section{Acute mania and mixed episodes of bipolar I disorder}

Vieta et al performed a study to investigate the efficacy of PER in patients with acute manic or mixed episodes of bipolar I disorder and secondarily to assess noninferiority of paliperidone versus quetiapine (as an active comparator) over 12 weeks of treatment. ${ }^{68}$ The study consisted of a threeweek, double-blind, acute treatment phase, during which patients were randomly assigned in a 2:2:1 ratio to receive PER 3-12 mg/day (flexibly dosed), quetiapine 400$800 \mathrm{mg} /$ day (initially titrated and flexibly dosed), or placebo. This phase was followed by a nine-week, double-blind maintenance phase, during which patients continued with flexible doses of their recent study medication, whereas patients on placebo were switched, in a blinded fashion, to flexibly dosed PER at an initial dose of $6 \mathrm{mg} /$ day. Patients needed to have at least one documented manic or mixed episode requiring treatment within the three years prior to screening and a YMRS ${ }^{67}$ of $\geq 20$ at screening at baseline. Primary efficacy variable was the change from baseline in YMRS total score at the three-week endpoint for PER versus placebo. The key secondary efficacy variable was the change from baseline in Global Assessment of Functioning score at the three-week endpoint for PER versus placebo. Other secondary efficacy variables included a noninferiority analysis of PER and quetiapine, based on change in YMRS score at the 12-week endpoint. Additional endpoints were change in PANSS and CGI-Bipolar Disorder-Severity score (CGIBP-S). ${ }^{69}$ Of the 643 patients screened, 493 met the eligibility criteria, and were randomly assigned to the treatment groups, and 232 patients completed the entire 12-week study. PER was superior to the placebo in the reduction of YMRS scores at the three-week endpoint $(P<0.001)$ and noninferior to quetiapine at the 12-week endpoint. There was no significant difference between PER and quetiapine in onset of therapeutic effect, responder rate, and remission rate. A higher percentage of PER than quetiapine patients (13.9\% versus $7.5 \%$, respectively) showed symptoms of depression at the 12 -week endpoint. The median mode dose during the 12-week treatment period was $9 \mathrm{mg}$ for PER and $600 \mathrm{mg}$ for quetiapine. The authors concluded that PER was effective and tolerable in the treatment of acute mania. 


\section{Other therapeutic options}

Although paliperidone is the active metabolite of risperidone and shares some similarities in its receptor binding profile with that of risperidone, it has been suggested that paliperidone is pharmacologically distinct from its parent compound..$^{70}$ Dremencov et al used animal data ${ }^{70}$ to show that paliperidone differentially affects serotonin and norepinephrine neuronal firing compared with risperidone when used in combination with selective serotonin re-uptake inhibitors. Based on animal studies, it has been suggested that paliperidone may be especially useful in the treatment of depression in patients resistant to selective serotonin reuptake inhibitors. ${ }^{70}$ Corena-McLeod et $\mathrm{al}^{71}$ hypothesized that paliperidone could be used as a mood disorder stabilizer in patients with bipolar disorder. For that purpose, they focused on the protein profile of synaptoneurosomes isolated from the prefrontal cortex of the rat brain, because this cerebral structure has been linked to the pathophysiology of mood disorders. Synaptoneurosomal-enriched protein preparations include a collection of pre- and postsynaptic proteins involved in a variety of pathways, including intracellular calcium signaling, energy metabolism, and neuronal plasticity. The authors intend to determine changes in expression in synaptoneurosomal-enriched prefrontal cortex preparations of the rat brain after chronic treatment with paliperidone, lithium, and valproate. Similar protein expression profiles at the synaptoneurosomal level have been observed, suggesting that the mode of action of paliperidone is similar to that of lithium and valproic acid. The expression profile for paliperidone is similar to that of lithium, implicating the effects of paliperidone on signaling pathways, energy metabolism, and synaptic plasticity. With these findings showing that paliperidone induces similar changes in synaptoneurosomal protein expression as lithium in an animal model, paliperidone could act as a mood stabilizer as its mode of action is similar to lithium.

\section{Critical appraisal of existing data}

There is clearly some evidence that PER is more effective in the treatment of schizophrenic symptoms than placebo. However, data are primarily based on only three reasonably powered studies funded by the producing company. Head-to-head comparisons, especially with risperidone, have been avoided, although easily possible because some studies have used quetiapine or olanzapine as comparator substances. A number of post hoc analyses were performed with existing data. All assumptions made were not part of the original research questions. No intention-to-treat analyses were performed, which is a major drawback in the face of high dropout rates. Animal studies were used to hypothesize the efficacy of PER as a mood stabilizer. Without any real in vivo evidence, this remains pure speculation. In summary, there is little evidence from direct research to answer questions beyond the efficacy of PER for schizophrenia and acute mania. Possible data that could have given answers about the place of PER amongst existing treatments were not used, collected, or analyzed, casting some doubt on the intention to find out whether there is any superiority of PER compared with other antipsychotics justifying its significantly higher cost. Instead, assumptions about the efficacy of PER in many areas are made without direct research evidence, support coming merely from post hoc analyses of limited value.

\section{Safety and tolerability}

Studies that directly compared the profile of side effects of PER and its parent compound, risperidone, were not found. A study by Sun et $\mathrm{al}^{72}$ investigated the acute toxicity of PER and its derivatives in mice and rats. To maintain a comprehensive view on the safety and tolerability of PER in human subjects and patients, we reviewed the adverse side effects that occurred in the published efficacy studies of Marder et al, Kane et al, Davidson et al, ${ }^{44}{ }^{46}$ and the symptom recurrence study by Kramer. ${ }^{61}$ We reviewed the pooled analysis of these three studies by Meltzer, ${ }^{53}$ the 52-week long-term pooled analysis of the aforementioned efficacy studies, ${ }^{52} \mathrm{a}$ study comparing quetiapine and PER in patients with recently diagnosed schizophrenia, ${ }^{64}$ as well as a study on the safety and tolerability of PER in elderly patients with schizophrenia. ${ }^{59}$ Table 2 displays side effects as observed in the three pivotal clinical trials in schizophrenia, and Table 3 shows the side effects of PER treatment in elderly schizophrenic patients.

In general, PER was well tolerated by patients with schizophrenia treated within the three six- week studies and the 52-week long-term study. Table 2 shows the pooled data on adverse side effects that occurred during the three six-week placebo-controlled trials. In the three six-week trials, serious adverse events (5\%-6\%) and dropouts due to adverse events $(2 \%-7 \%)$ were similar in patients treated with PER and placebo (6\% and 5\%).

The pooled analysis of three long-term, open-label studies showed that PER was well tolerated over a 52-week treatment duration..$^{52}$ Again, the most frequent serious adverse events were psychotic disorders with a rate of $5 \%$, and depression, suicidal ideation, suicide attempts, and agitation, with a rate 
Table 2 Side effects of paliperidone extended release from pooled data of the three efficacy studies in schizophrenia*

\begin{tabular}{|c|c|c|c|c|c|c|c|}
\hline & \multirow{2}{*}{$\begin{array}{l}\text { Placebo } \\
-\end{array}$} & \multicolumn{5}{|c|}{ Paliperidone ER } & \multirow{3}{*}{$\begin{array}{l}\text { Total } \\
(n=963) n(\%)\end{array}$} \\
\hline & & $3 \mathbf{m g}$ & $6 \mathrm{mg}$ & $9 \mathrm{mg}$ & $12 \mathrm{mg}$ & $15 \mathrm{mg}$ & \\
\hline & $(n=355) n(\%)$ & $(n=127) n(\%)$ & $(n=235) n(\%)$ & $(n=246) n(\%)$ & $(n=242) n(\%)$ & $(n=113) n(\%)$ & \\
\hline TEAEs in total & $235(66)$ & $91(72)$ & $156(66)$ & I7| (70) & $184(76)$ & $87(77)$ & $689(72)$ \\
\hline \multicolumn{8}{|l|}{ CNS disorders } \\
\hline Headache & $42(12)$ & $14(1 \mathrm{I})$ & $29(12)$ & $34(14)$ & $35(14)$ & $20(18)$ & $132(14)$ \\
\hline Akathisia & $14(4)$ & $5(4)$ & $7(3)$ & $20(8)$ & $23(10)$ & II (I0) & $66(7)$ \\
\hline $\begin{array}{l}\text { Extrapyramidal } \\
\text { disorder }\end{array}$ & $8(2)$ & $6(5)$ & $5(2)$ & $17(7)$ & $18(7)$ & $9(8)$ & $55(6)$ \\
\hline Somnolence & $12(3)$ & $6(5)$ & $8(3)$ & $17(7)$ & II (5) & $7(6)$ & $49(5)$ \\
\hline Dizziness & $14(4)$ & $7(6)$ & II (5) & II (4) & $12(5)$ & $7(6)$ & $48(5)$ \\
\hline Sedation & $13(4)$ & $\mathrm{I}(\mathrm{I})$ & $12(5)$ & $8(3)$ & $15(6)$ & $2(2)$ & $38(4)$ \\
\hline \multicolumn{8}{|c|}{ Psychiatric disorders } \\
\hline Insomnia & $51(4)$ & $14(11)$ & $29(12)$ & $35(14)$ & $26(11)$ & $14(12)$ & $118(12)$ \\
\hline Anxiety & $29(8)$ & $12(9)$ & $16(7)$ & $14(6)$ & II (5) & $9(8)$ & $62(6)$ \\
\hline Agitation & $28(8)$ & $7(6)$ & $17(7)$ & $13(5)$ & $13(5)$ & $3(3)$ & $53(6)$ \\
\hline Psychotic & $16(5)$ & $5(4)$ & $6(3)$ & $7(3)$ & $4(2)$ & $4(4)$ & $26(3)$ \\
\hline Disorders & & & & & & & \\
\hline \multicolumn{8}{|c|}{ Gastrointestinal disorders } \\
\hline Nausea & $19(5)$ & $8(6)$ & $9(4)$ & $10(4)$ & $10(4)$ & $2(2)$ & $39(4)$ \\
\hline Vomiting & $17(5)$ & $2(2)$ & $6(3)$ & $9(4)$ & $12(5)$ & $8(7)$ & $37(4)$ \\
\hline Constipation & $20(6)$ & $7(6)$ & $8(3)$ & $7(3)$ & $7(3)$ & $4(4)$ & $33(3)$ \\
\hline Dyspepsia & $14(4)$ & $3(2)$ & $6(3)$ & $5(2)$ & $12(5)$ & $6(5)$ & $32(3)$ \\
\hline \multicolumn{8}{|c|}{ Cardiac disorders } \\
\hline Tachycardia & $10(3)$ & $3(2)$ & $17(7)$ & $18(7)$ & $18(7)$ & $2(2)$ & $58(6)$ \\
\hline $\begin{array}{l}\text { Sinus } \\
\text { tachycardia }\end{array}$ & $15(4)$ & II (9) & $9(4)$ & $10(4)$ & $17(7)$ & $8(7)$ & $55(6)$ \\
\hline $\begin{array}{l}\text { QTc } \\
\text { prolongation }\end{array}$ & $9(3)$ & $4(3)$ & $9(4)$ & $7(3)$ & $12(5)$ & $4(4)$ & $36(4)$ \\
\hline
\end{tabular}

Note: *Adapted from Meltzer et al. ${ }^{53}$

Abbreviations: TEAE, Treatment-emergent adverse events; ER, extended release.

of $1 \% .^{52}$ Treatment-emergent adverse events were observed in $76 \%$ of the patients treated with PER, $7 \%$ were dropouts due to adverse events, and two patients committed suicide (enrolled $\mathrm{n}=1083$, completed $\mathrm{n}=507$ ). Most frequently noted treatment-emergent adverse events were insomnia (14\%), headache (12\%), and akathisia (11\%).

The study by Canuso et al, ${ }^{64}$ which compared the efficacy and safety of quetiapine and PER in patients recently diagnosed with schizophrenia, found tremor, somnolence, and insomnia to be the most common adverse events during a two-week period, and tremor, somnolence, sedation, and insomnia during a six-week period. Serious adverse events were reported in $2.5 \%$ of patients treated with placebo, $4.4 \%$ of patients treated with quetiapine, and $8.2 \%$ of patients treated with PER.

The study by Tzimos et al ${ }^{59}$ investigating the safety and tolerability of PER in elderly patients with schizophrenia reported serious adverse events in 3\% of the PER group (acute coronary syndrome in one patient and mania in one patient) and $8 \%$ of the placebo group during the double-blind study phase. Treatment-emergent adverse events were seen at similar rates in placebo (71\%) and PER (67\%) groups.

\section{Acute toxicity}

Sun et $\mathrm{al}^{72}$ investigated the acute toxicity of risperidone, PER, and its derivatives in mice and rats. They found $\mathrm{LD}_{50}$ of $50.89 \mathrm{mg} / \mathrm{kg}$ body weight for risperidone and $162.65 \mathrm{mg} / \mathrm{kg}$ for PER. The maximum tolerated dose was $5.78 \mathrm{mg} / \mathrm{kg}$ for risperidone and $4.11 \mathrm{mg} / \mathrm{kg}$ for PER. The maximum tolerated dose was defined as the maximum drug dosage that did not lead to toxic manifestations or death in the experimental animals. Hence, PER seems to be at an advantage regarding lethal doses in animals, but surprisingly inferior compared with risperidone for tolerability.

\section{Extrapyramidal symptoms}

Pooled data from three six-week efficacy studies show a nonlinear dose-dependent increase of extrapyramidal symptoms with rates of $13 \%, 10 \%, 25 \%$, and $26 \%$ in patients treated with PER 3, 6, 9, and $12 \mathrm{mg}$, and $11 \%$ 
Table 3 Safety and Tolerability in Elderly Patients*

\begin{tabular}{|c|c|c|c|c|}
\hline & \multicolumn{2}{|l|}{ Double-blind } & \multicolumn{2}{|l|}{ Open-label } \\
\hline & Placebo $(n=38)$ & PER $(n=76)$ & Placebo/PER $(n=30)$ & PER/PER $(n=58)$ \\
\hline \multicolumn{5}{|l|}{ Treatment-emergent adverse events } \\
\hline \multicolumn{5}{|l|}{ Overall } \\
\hline All TEAEs & 27 (7I) & $51(67)$ & $24(80)$ & $43(74)$ \\
\hline Possibly related TEAE & $17(45)$ & $38(50)$ & $12(40)$ & $26(45)$ \\
\hline TEAE leading to death & $2(5)$ & 0 & 0 & 0 \\
\hline Any serious TEAE & $3(8)$ & $2(3)$ & $3(7)$ & $3(5)$ \\
\hline TEAE leading to discontinuation & $3(8)$ & $5(7)$ & $3(10)$ & $3(5)$ \\
\hline \multicolumn{5}{|c|}{ Occurrence $\geq 5 \%$ in any treatment group } \\
\hline Nervous system disorders & $9(24)$ & $22(29)$ & $8(27)$ & $14(24)$ \\
\hline Extrapyramidal disorder & $4(\mathrm{II})$ & $4(5)$ & $2(7)$ & $3(5)$ \\
\hline Somnolence & $2(5)$ & $7(9)$ & $2(7)$ & 0 \\
\hline Dizziness & 0 & $5(7)$ & I (3) & $6(10)$ \\
\hline Headache & I (3) & $4(5)$ & $3(10)$ & $5(9)$ \\
\hline Cardiac disorders & $5(13)$ & $20(26)$ & $8(27)$ & $11(19)$ \\
\hline Tachycardia & 0 & $12(16)$ & $4(13)$ & $6(10)$ \\
\hline Psychiatric disorders & $9(24)$ & $11(14)$ & $3(10)$ & $14(24)$ \\
\hline Insomnia & $4(\mathrm{II})$ & 7 (9) & I (3) & $9(16)$ \\
\hline Agitation & $2(5)$ & $2(3)$ & 0 & $2(3)$ \\
\hline Anxiety & $2(5)$ & $2(3)$ & 0 & $3(5)$ \\
\hline Investigations & $5(13)$ & $7(9)$ & $5(17)$ & $12(2 \mid)$ \\
\hline QTc prolongation & $I(3)$ & $5(7)$ & $3(10)$ & $2(3)$ \\
\hline Electrocardiographic $\mathrm{T}$ wave inversion & $2(5)$ & $I(1)$ & 0 & $2(3)$ \\
\hline Gastrointestinal disorders & $7(18)$ & $7(9)$ & $2(7)$ & $3(5)$ \\
\hline Nausea & $2(5)$ & $2(3)$ & 0 & 0 \\
\hline Vomiting & $2(5)$ & $I(I)$ & 0 & I (2) \\
\hline General disorders & $2(5)$ & $5(7)$ & $5(17)$ & $10(17)$ \\
\hline Asthenia & $2(5)$ & $4(5)$ & $4(13)$ & $8(14)$ \\
\hline Fatigue & 0 & $I(I)$ & 0 & $3(5)$ \\
\hline Infections and infestations & $6(16)$ & $8(11)$ & $5(17)$ & $7(12)$ \\
\hline Nasopharyngitis & I (3) & 0 & $2(7)$ & $3(5)$ \\
\hline Pneumonia & I (3) & $\mathrm{I}(\mathrm{I})$ & $2(7)$ & 0 \\
\hline Vascular disorders & $2(5)$ & $8(11)$ & 0 & $3(5)$ \\
\hline Hypertension & I (3) & $4(5)$ & 0 & $2(3)$ \\
\hline Hypotension & 0 & $4(5)$ & 0 & $I(2)$ \\
\hline
\end{tabular}

Note: *Adapted from Tzimos et al. ${ }^{59}$

Abbreviations: PER, paliperidone extended-release; n, number of subjects; TEAE, treatment-emergent adverse events.

in placebo-treated patients. ${ }^{53}$ Akathisia, parkinsonism, dyskinesia, and dystonia were the most often reported extrapyramidal side effects. Only a single case of tardive dyskinesia was observed with PER across the studies. The Abnormal Involuntary Movement Scale, Barns Akathisia Rating scale, and Simpson Angus Rating scale did not show significant median deviations across the dosage spectrum studied. Still, patients treated with the higher doses, ie, PER $9 \mathrm{mg}$ and $12 \mathrm{mg}$, showed extrapyramidal symptoms more often.

In pooled data from the 52-week open-label studies, $23 \%-25 \%$ of patients treated with PER developed extrapyramidal symptoms at a mean dosage of $10 \mathrm{mg} .{ }^{52}$ This was similar to patients who were treated with olanzapine or placebo during the six-week double-blind study phase and subsequently shifted to open-label PER treatment (23\%-25\% and $32 \%$ ).

The study comparing quetiapine and $\mathrm{PER}^{64}$ found a higher incidence of extrapyramidal symptoms in the first two weeks on PER compared with quetiapine but not compared with placebo. After six weeks, there was no significant difference between the treatment groups with respect to extrapyramidal symptoms.

In elderly patients, the incidence of extrapyramidal symptoms was low throughout the double-blind and open-label study phases. ${ }^{59}$ Extrapyramidal disorders occurred more often in the placebo group during the double-blind phase, but akathisia rates were identical for PER and placebo at 3\%. None of these events resulted in discontinuation. 


\section{Metabolic effects}

In the three six-week, double-blind, placebo-controlled studies, ${ }^{53}$ the mean increase in body weight was $0.6,0.6,1.0$, 1.1 , and $1.9 \mathrm{~kg}$ on PER 3, 6, 9, 12, and $15 \mathrm{mg} /$ day. Mean body weight change in the placebo groups was $-0.4 \mathrm{~kg}$ and mean body weight increase in the olanzapine groups was $2.0 \mathrm{~kg}$. In the 52-week extension-phase of the three six-week studies, the mean body weight increase in all treatment groups was $1.1 \mathrm{~kg}$, with an overall mean modal dose of PER $10 \mathrm{mg} .{ }^{52}$ Compared with PER or placebo, quetiapine was associated with a significantly higher body weight increase of $0.8 \mathrm{~kg}$ versus $0.4 / 0.2 \mathrm{~kg}$ after two weeks and 1.1 versus $0.4 / 0.3 \mathrm{~kg}$ after six weeks. ${ }^{64}$ In elderly patients, there was no increase in mean body weight or body mass index in the active and placebo groups. ${ }^{59}$

Glucose metabolism was slightly affected by PER in the three placebo-controlled clinical trials (pooled data) with no significant difference between PER and placebo groups (rate of glucose-related adverse events was $1 \%$ each). ${ }^{53}$ This was confirmed in the 52-week extension, during which the incidence of deranged glucose metabolism was also $1 \%$ in patients treated with PER. ${ }^{52}$

\section{Cardiovascular side effects}

With respect to cardiovascular side effects, PER was well tolerated in normal-aged patients, with a slightly increased incidence of cardiovascular side effects among elderly patients. ${ }^{53,59}$ In the pooled analysis of the three six-week studies, there were no clinically relevant differences in treatmentemergent adverse effects suggestive of a proarrhythmic potential between placebo or any PER treatment group. Syncope was reported in a low percentage of patients receiving PER (0.8\%), similar to the rate reported for placebo ( $1 \%)$. Mean QTc interval prolongation differences between patients treated with PER and patients treated with placebo were negligible $(<4 \mathrm{msec})$. There was no significant difference between PER and placebo regarding QTc intervals $>450 \mathrm{msec}$ and $<480 \mathrm{msec}$. No patient treated with PER irrespective of dosage showed a QTc interval of $\geq 480 \mathrm{msec}$ in the three clinical placebo-controlled trials.

In the study investigating safety and tolerability in elderly patients, ${ }^{59}$ there were QTc intervals $\geq 500$ msec reported in two patients treated with PER during the six-week study phase and in one patient during the 24-week extension phase. All of the three patients had a history of cardiovascular disease and QTc prolongation. The study comparing quetiapine and PER did not verify any significant QTc prolongation in PER-treated or in quetiapine-treated patients. ${ }^{64}$
Prescribing information for PER regarding prolongation of the QT interval contains stronger warnings than that for risperidone..$^{34}$ The manufacturer recommends avoiding the concomitant use of PER with medication known to prolong the QTc interval, such as quinidine, amiodarone, sotalol, chlorpromazine, thioridazine, gatifloxazine, and moxifloxazine. ${ }^{34}$

\section{Endocrine side effects}

The three double-blind, six-week studies found significantly elevated plasma prolactin levels at the six-week endpoint in patients treated with PER compared with baseline. ${ }^{53}$ This increase was dose-related, with mean endpoint prolactin concentrations of $130.1 \mathrm{ng} / \mathrm{mL}$ for female patients and $52.8 \mathrm{ng} / \mathrm{mL}$ for male patients treated with PER $15 \mathrm{mg}$ daily (reference range $1.39-24.20 \mathrm{ng} / \mathrm{mL}$ for females, $1.61-18.77 \mathrm{ng} / \mathrm{mL}$ for males). Mean prolactin concentration in the placebo groups was $20.8 \mathrm{ng} / \mathrm{mL}$ (for females) and $12.5 \mathrm{ng} / \mathrm{mL}$ (for males). Prolactin levels remained elevated during the 52-week extension. ${ }^{52}$ There was no significant difference between PER and placebo regarding the incidence of probably prolactin-related adverse events in the three sixweek trials (pooled data). ${ }^{53}$ Sexual dysfunction, gynecomastia, galactorrhea, amenorrhea, and menstrual dysregulation occurred with an incidence of $1 \%-2 \%$ during the 52-week extension. The incidence of amenorrhea and menstrual dysregulation increased to $4 \%$ and $5 \%$, respectively, in the female study population. ${ }^{52}$

In the study investigating safety and tolerability in elderly patients,${ }^{59}$ no potentially prolactin-related adverse events were reported for any of the patients throughout the double-blind phase or the open-label extension of the study. Nevertheless, elevated prolactin levels were reported for $45 \%$ of the males and $49 \%$ of the females treated with PER. At the double-blind endpoint, median prolactin levels were $85.3 \mathrm{ng} / \mathrm{mL}$ in females and $32.0 \mathrm{ng} / \mathrm{mL}$ in males treated with PER, ${ }^{59}$ ie, they were almost four-fold above the normal range in females and elevated by almost two-fold in males. It is likely that these elevations would have an effect on bone density.

A small study examined the relationship between risperidone, 9-hydroxyrisperidone (ie, paliperidone), and serum prolactin levels in 25 patients with psychotic disorders. The oral dose of risperidone correlated significantly with plasma concentrations of risperidone, 9-hydroxy-risperidone (the active moiety), and prolactin. The plasma concentration of 9-hydroxy-risperidone, but not of risperidone, correlated significantly with increases in plasma prolactin. The authors 
concluded that 9-hydroxy-risperidone may play a major role in causing hyperprolactinemia. ${ }^{73}$ The authors hypothesized that this hyperprolactinemia may be related to paliperidone's lower lipophilia and longer half-life, both of which increase paliperidone's ability to affect the anterior pituitary gland. As a result of dopamine receptor blockade, the anterior pituitary gland, located outside the blood-brain barrier, produces prolactin when stimulated. ${ }^{73}$

Berwaerts et a ${ }^{66}$ clearly showed in 37 subjects that serum prolactin levels on risperidone as compared with PER show higher peak-trough-fluctuations. Mean prolactin levels with risperidone were higher than with PER (mean $89.7 \pm 57.4$ versus $71.8 \pm 60.8 \mathrm{ng} / \mathrm{mL}$ ), and that these differences diminished until day $6(71.4 \pm 61.5$ versus $68.5 \pm 52.6 \mathrm{ng} / \mathrm{mL})$. The authors concluded that from a short-term one-week perspective, PER and risperidone result in similar prolactin levels.

It may be due to the OROS formulation that PER shows lower peak drug serum levels than risperidone during the titration phase. Furthermore, prolactin shows lower peaks on PER than on risperidone. Lower serum peak levels of the active substance, as well as of prolactin, may be the reason for the low incidence of prolactin-related side effects in spite of markedly increased prolactin levels in patients treated with PER.

\section{Other reported side effects}

In the literature, there are two cases with possible malignant neuroleptic syndrome related to treatment with PER. ${ }^{74,75}$ In the reported cases, possible malignant neuroleptic syndrome occurred at a dosage of $9 \mathrm{mg} / \mathrm{day}$. There is also one case report indicating that PER is capable of inducing mania when administered for the treatment of paranoid schizophrenia at a dosage of $9 \mathrm{mg} /$ day. ${ }^{76}$ In a recently published case report, hepatitis occurred on treatment with clozapine and risperidone, and hepatic failure subsided after switching from risperidone to PER, with only a slightly reduced clozapine dosage. ${ }^{77}$ When used in elderly patients with psychosis associated with dementia, PER, like all other atypical antipsychotics, has an increased risk of mortality. ${ }^{34}$ Another possible limitation of PER is its availability only in the OROS formulation that, as a consequence of its nondeformability and inflexibility, precludes crushing or chewing of the substance and also inhibits its application in patients suffering from severe gastrointestinal narrowing.

\section{Potential for abuse and dependence}

In a Medline search and a separate investigation of the databases of the US Food and Drug Administration and www.clinicaltrials.com, we could not detect any studies that systematically investigated the potential of PER to induce abuse or substance dependence. There were also no case reports showing PER as an agent liable to abuse or causing dependence. In light of this, it is not possible to give evidence concerning the potential of PER to be misused, abused, or cause tolerance or physical dependence.

\section{Conclusion concerning adverse effects}

With respect to the published literature on safety and tolerability so far, PER seems to be well tolerated and safe to use as a second-generation antipsychotic. Its primary limitations are prolactin elevation and extrapyramidal symptoms, both of which seem to be dose-related. It is noteworthy that the prolactin increase and incidence of potentially prolactinassociated adverse events do not increase to the same extent. Weight gain increases are also verifiable, but less pronounced, than with other second-generation antipsychotics such as olanzapine or quetiapine. PER should be prescribed carefully in elderly patients because of the potential for QTc prolongation, especially when there is a history of cardiovascular disease.

\section{Patient-focused perspectives}

In addition to rapid symptom control, predominantly judged by the physician, patient satisfaction with treatment is increasingly recognized as an important outcome measure. Recent studies suggest that patient satisfaction is an important measure of the effectiveness of treatment. ${ }^{78}$ Patient satisfaction with antipsychotic medication plays an important role, ${ }^{78}$ because it is positively associated with improved therapy adherence, improved clinical outcomes, and quality of life. ${ }^{79}$ To our knowledge, there are no specific clinical trials focusing on PER treatment and its influence on quality of life. There are only studies that have investigated either separate aspects of the "quality of life complex" or concomitantly assessed quality of life performance or satisfaction with medication within a study setting focusing on different primary outcome measures.

Canuso et $\mathrm{al}^{80}$ conducted a randomized, six-week, prospective, blinded initiation study to evaluate satisfaction with medication in patients with a suboptimal response to oral risperidone and switching to PER. Eligible patients were outpatients who continued to be symptomatic despite risperidone 4 or $6 \mathrm{mg}$ /day for at least four weeks before randomization. Three main inclusion criteria had to be met, ie, score $\geq 4$ on at least three specified PANSS items, reported dissatisfaction with current medication as measured by score $\leq 3$ (extremely to somewhat 
dissatisfied) on item 14 ("taking all things into account, how satisfied or dissatisfied are you with this medication?") of the Treatment Satisfaction Questionnaire for Medication, ${ }^{81}$ and, in the investigator's opinion, the patient could benefit from a change in antipsychotic medication.

At the baseline visit, participants were randomly assigned in a 1:1 ratio to either immediate PER $6 \mathrm{mg} /$ day (from day 1) or delayed initiation of PER (after two weeks with stable baseline dose of risperidone switching to PER $6 \mathrm{mg} /$ day on day 15) in a double-blind setting. The treatment period for both groups was six weeks, with possible PER changes in $3 \mathrm{mg}$ increments starting four days after drug initiation. A one-item patient-reported medication satisfaction questionnaire (MSQ, a patient-reported seven-point Likert-scale ranging from 1 (extremely dissatisfied) to 7 (extremely satisfied) at two fixed points in time), consisting of the single question "Overall, how satisfied are you with our current antipsychotic medication(s)?" was evaluated at baseline and at weeks 2, 4, and 6. Item 14 of the Treatment Satisfaction Questionnaire for Medication was also used. Two hundred and one patients were screened and randomized, and 191 were included. In the overall population, the mean \pm standard deviation MSQ score improved from $2.7 \pm 0.8$ at baseline to $5.1 \pm 1.2$ at endpoint $(P<0.001)$. On the basis of dichotomized analysis of the MSQ scale, $82.7 \%$ of participants were satisfied with their medication at endpoint. At the two-week time point, more participants in the immediate initiation group reported satisfaction $(67.7 \%)$ compared with those in the delayed initiation group $(45.3 \%)$ who were still receiving risperidone at this time $(P=0.002)$. Treatment Satisfaction Questionnaire for Medication score improved significantly at any point of time, with no significant between-group differences at any time. The authors concluded that participants with schizophrenia who were suboptimally responsive to risperidone reported improved medication satisfaction after initiation of PER. It remains unclear why PANSS score changes were not used as an outcome measure. This is, however, in keeping with the industry's reluctance to fund head-to-head studies in these circumstances.

In the study by Kramer et al, ${ }^{61}$ the primary efficacy variable was symptom recurrence under treatment with PER after an acute exacerbation of the disease. Secondary efficacy measures also included quality of life, assessed by the Schizophrenia Quality of Life Scale. ${ }^{60}$ However, the authors only mentioned significant improvements in scores on this instrument compared with placebo without presenting detailed results.
The study of Tzimos et al ${ }^{59}$ primarily investigated the safety and tolerability of PER in elderly patients. They also performed an assessment of quality of life using the Schizophrenia Quality of Life Scale ${ }^{60}$ as a secondary efficacy measure. Although no formal statistical analysis was conducted, the authors reported no detected differences between the two groups (active versus placebo) as measured by the Schizophrenia Quality of Life Scale scores.

Canuso et $\mathrm{al}^{64}$ performed a study to compare the shortterm efficacy and safety of PER versus quetiapine in patients with recently exacerbated schizophrenia. Participants were administered the MSQ. ${ }^{82}$ Mean changes in the scores of this instrument showed a nonsignificant trend in the direction of more treatment satisfaction in the group treated with PER as compared with quetiapine or placebo, whereas mean changes with quetiapine and placebo were comparable.

\section{Conclusion}

This is the first independent review of PER. We aimed to determine its place in modern antipsychotic therapy and tried to compare PER with its precursor, risperidone, in view of mounting concerns about its cost-effectiveness. PER was first approved for the treatment of schizophrenia in 2006 in the US. The three short-term, randomized, double-blind, placebo-controlled clinical trials conducted so far have documented that PER 3-15 mg/day appears to be efficacious, safe, and well tolerated in adult patients with schizophrenia. Long-term data confirmed the findings of the short-term trials and indicated low liability to cause metabolic effects, such as weight gain, hyperglycemia, and lipid dysregulation. Effects on prolactin are substantial. The efficacy and tolerability of PER in the treatment of schizoaffective disorder and acute manic episodes has also been demonstrated in the clinical trials.

At this time, there are no published data for randomized controlled head-to-head comparisons of PER with risperidone, and we found no data examining the utility of PER in patients previously intolerant to risperidone or for whom risperidone was ineffective. Therefore, a final answer to the important question "Is PER worth the extra cost?" is not possible at the moment. As a consequence, and given that there are no ongoing head-to-head trials comparing PER with risperidone (according to www.clinicaltrials.com), there is a definite need for at least further indirect comparisons of the substances. Taking into account the high percentage of author groups with a direct affiliation to the manufacturer of PER (especially when regarding review articles dealing with PER) further studies should be performed by independent 
researchers. It is impossible to conclude from the currently available data that PER is superior to risperidone. It does, however, confer certain advantages for a limited group of patients who cannot continue successful risperidone therapy.

Our main findings can be summarized as follows:

- PER appears to be an efficacious and well tolerated treatment for schizophrenia and schizoaffective disorder, reflecting its approval status

- Existing evidence on PER originates from a limited number of studies that meet high methodological requirements

- Our review revealed a striking lack of published head-tohead comparisons of PER with its mother substance and predecessor risperidone, although they were both first introduced to the market by the same manufacturer

- PER differs from risperidone in a number of its pharmacological properties

- In the absence of direct and naturalistic PER versus risperidone studies we cannot decide whether the substantially higher daily drug costs of PER are counterbalanced by clear advantages over risperidone in terms of efficacy or tolerability.

\section{Role in modern pharmacotherapy}

It is clear that PER and its mother substance, risperidone, are by no means identical in terms of pharmacology. In other words, risperidone and its active metabolite 9-hydroxyrisperidone, particularly when combined with the OROS technology, can be considered to be two distinct antipsychotics. PER offers some obvious advantages in pharmacokinetic properties compared with risperidone. From a pharmacological perspective, PER differs from all available antipsychotics. This clearly leaves room for PER in the still limited arsenal of so-called second-generation antipsychotics.

With regard to pharmacokinetic and pharmacodynamic properties, PER offers several meaningful advantages. Taking into account the high proportion of patients with schizophrenia who have comorbid hepatic impairment, ${ }^{83}$ the predominantly renal elimination of paliperidone appears to be an advantage (eg, in cases where amisulpride is not an option). Negligible hepatic metabolism is one of the two main differences between PER and its parent compound risperidone. At least theoretically, it is also less prone to pharmacogenetic effects associated with CYP 2D6 ultrarapid or poor metabolizer status. Compared with risperidone, PER has a lower risk of causing hepatic drug-drug-interactions, particularly in multimorbid patients with polypharmacy. The possibility of obtaining smooth drug plasma levels using the OROS system accompanied by a once-daily formulation and no need for dose titration is the second specific property of PER. These improved pharmacological properties should enlarge the population of patients that can benefit from antipsychotic therapy with PER, and might improve symptom control and compliance in patients who have already responded positively to risperidone.

Because the shell of PER is nonabsorbable, it will appear in feces and possibly cause concern in patients with acute or paranoid psychopathology. Detailed patient information about this aspect, should given routinely, although this method of excretion could limit the use of PER in some patient groups.

We conclude that PER offers distinct and specific benefits resulting from its pharmacokinetic profile. This renders it potentially useful in a limited group of patients who have responded to risperidone but are unable to continue with risperidone treatment for a variety of reasons:

- Its primarily renal metabolism makes PER a treatment of choice in those with hepatic impairment who have previously responded to risperidone

- Its long half-life makes PER a treatment of choice in those with limited compliance who have previously responded to risperidone but cannot be persuaded to accept a intramuscular depot medication with risperidone microspheres

- Its relatively favorable extrapyramidal side effect profile makes PER a treatment of choice in those who have responded to risperidone but could not tolerate its extrapyramidal side effects.

Despite theoretically convincing benefits for selected patients, financial costs seem to be the limiting factor in administering PER. The commissioners of health care criticize PER as a pseudoinnovation without added advantages over its mother substance. This position cannot be justified in light of the data presented here. One may want to criticize the price policy of the manufacturer as well as the very restrictive position of health care commissioners, but the relationship between additional costs and actual therapeutic advantage over risperidone is a crucial and legitimate point. Similar problems have arisen with the use of escitalopram (versus citalopram) and valproate semisodium (versus valproate chrono). The price policy of Janssen-Cilag led to a refusal of drug cost reimbursement higher than that of risperidone by health care providers (Table 4 shows a comparison of costs of daily drug doses in Germany between PER and risperidone). This led to de facto withdrawal of the drug in Germany, because the majority of patients who could potentially benefit from the special characteristics of the drug are not able to pay the daily costs of PER themselves. 
Table 4 Daily Drug costs of PER vs. Risperidone in Germany (Risperdal and its cheapest generic drug)

\begin{tabular}{ll}
\hline Substance & Daily invega \\
\hline Invega $9 \mathrm{mg} /$ day & $€ 7.10$ \\
Risperdal $4 \mathrm{mg} /$ day & $€ 1.36$ \\
Risperidone $4 \mathrm{mg} /$ day & $€ 0.32$ \\
\hline
\end{tabular}

Note: Calculation based on 98 tablets/package for PER and 100 tablets/package for risperidone.

Abbreviation: PER, paliperidone extended-release.

Pharmacoeconomic considerations are one of the main factors in the course of deciding whether PER offers an overall improvement in antipsychotic treatment compared with other agents, especially risperidone. Three cost-effectiveness analyses have shown PER to yield better outcomes and lower costs than alternative antipsychotics in patients with schizophrenia in Greece, ${ }^{84}$ the US ${ }^{85}$ (with estimated annual cost savings of US\$793 in favor of PER as compared with oral risperidone), and Italy. ${ }^{86} \mathrm{An}$ important limitation of the results of these studies is that the pharmacoeconomic models were not based on the results of head-to-head-trials, thus precluding accurate conclusions. With the availability of oral risperidone as a generic medication, the cost of oral PER will become a significant obstacle to its therapeutic use. In Germany, for example, the public health system terminated the financial support for PER in November 2009, resulting in additional costs for patients who stand to benefit from treatment with this antipsychotic. In the UK, many regional health care providers have limited PER to named patient use only.

Therefore, the treatment situation needs to be critically analyzed in order to balance increased financial contribution with the advantages of PER. We also have to acknowledge that PER was not part of any of the major meta-analyses that compared first-generation and second-generation antipsychotics. This further renders a final judgment on the PER's position among the other antipsychotics difficult. In short, existing evidence cautiously suggests a place for PER in modern antipsychotic therapy in terms of its unique pharmacology, irrespective of what future pharmacoeconomic studies will yield. Patients who may benefit from PER are limited to those who have responded to risperidone in the past, but are unable to continue on it because of compliance issues, extrapyramidal side effects, or hepatic impairment.

\section{Disclosure}

The authors report no conflicts of interest in this work.

\section{References}

1. Citrome L. Paliperidone: Quo vadis? Int J Clin Pract. 2007;61: 653-662.

2. Nussbaum AM, Stroup TS. Oral paliperidone for schizophrenia. Cochrane Database Syst Rev. 2008;2:CD006369.
3. Dolder C, Nelson M, Deyo Z. Paliperidone for schizophrenia. Am $J$ Health Syst Pharm. 2008;65:403-413.

4. Jones M, Nicholl D, Trakas K. Efficacy and tolerability of paliperidone ER and other oral atypical antipschotics in schizophrenia. Int $J$ Clin Pharmacol Ther. 2010;48:383-399.

5. Birnbaum M, Sharif Z. Medication adherence in schizophrenia: Patient perspectives and the clinical utility of paliperidone ER. Patient Prefer Adherence. 2008;2:233-240.

6. Spina E, Cavallaro R. The pharmacology and safety of paliperidone extended-release in the treatment of schizophrenia. Expert Opin Drug Saf. 2007;6:651-662.

7. Dlugosz H, Nasrallah A. Paliperidone: A new extended-release oral atypical antipsychotic. Expert Opin Pharmacother. 2007;8: 2307-2313.

8. Fowler J, Bettinger T, Argo T. Paliperidone extended-release tabletes for the acute and maintenance treatment of schizophrenia. Clin Ther. 2008;30:231-248

9. Janicak P, Winans E. Paliperidone ER: A review of the clinical trial data. Neuropsychiatr Dis Treat. 2007;3:869-883.

10. Yang L, Plosker G. Paliperidone extended release. CNS Drugs. 2007;21:417-425.

11. The World Health Report 2001. Mental Health: New Understanding, New Hope. Geneva: World Health Organization; 2001.

12. Lepping P, Delieu J, Mellor R, et al. Antipsychotic medication and oxidative cell stress: A systematic review. J Clin Psychiatry. June 29, 2010. [Epub ahead of print].

13. Swartz M, Stroup T, McEvoy J, et al. What CATIE found: Results from the schizophrenia trial. Psychiatr Serv. 2008;59:500-506.

14. Jones P, Barnes T, Davies L, et al. Randomized controlled trial of the effect on quality of life of second- vs first-generation antipsychotic drugs in schizophrenia: Cost Utility of the Latest Antipsychotic Drugs in Schizophrenia Study (CUTLASS 1). Arch Gen Psychiatry. 2006;63:1079-1087.

15. Leucht S, Corves C, Arbter D, et al. Second-generation versus firstgeneration antipsychotic drugs for schizophrenia: A meta-analysis. Lancet. 2009;373(9657):31-41.

16. Correll C, Schenk E. Tardive dyskinesia and new antipsychotics. Curr Opin Psychiatry. 2008;2:151-156.

17. Lepping P, Sambhi R, Whittington R, et al. A sytematic review of the clinical relevance of findings in trials of antipsychotics. Br J Psychiatry (in press). 2010

18. Heres S, Reichhart T, Hamann J, et al. Psychiatrists' attitude to antipsychotic depot treatment in patients with first-episode schizophrenia. Eur Psychiatry. June 4, 2010. [Epub ahead of print].

19. Hamann J, Mendel R, Heres S, et al. How much more effective do depot antipsychotics have to be compared to oral antipsychotics before they are prescribed? Eur Neuropsychopharmacol. 2010;20: 276-279.

20. Tungaraza T, Gupta S, Jones J, et al. Polypharmacy and highdose antipsychotic regimes in the community. The Psychiatrist. 2010;34:44-46.

21. Lepping P, Harborne G. Polypharmacy: How bad are we really. The Psychiatrist. 2010;34:208-209.

22. Karlsson P, Dencker E, Nyberg S, et al. Pharmacokinetics and dopamine D2 and serotonin 5-HT2A receptor occupancy of paliperidone in healthy subjects: Two open-label, single-dose studies. Clin Pharmacol Ther. 2006;79:74

23. Seeman P. An update of fast-off dopamine D2 atypical antipsychotics. Am J Psychiatry. 2005;162:1984-1985.

24. Arakawa R, Ito H, Takano A. Dose-finding study of paliperidone ER based on striatal and extrastriatal dopamine D2 receptor occupancy in patients with schizophrenia. Psychopharmacology (Berl). 2008;197:229-235.

25. Kapur S, Zipursky R, Jones C, Remington G, Houle S. Relationship between dopamine $\mathrm{D}(2)$ occupancy, clinical response, and side effects: A double-blind PET study of first-episode schizophrenia. Am J Psychiatry. 2000;157:514-520. 
26. Ereshefsky L, Mascarenas C. Comparison of the effects of different routes of antipsychotic administration on pharmacokinetics and pharmacodynamics. J Clin Psychiatry. 2003;64(Suppl 16):18-23.

27. Conley R, Gupta S, Sathyan G. Clinical spectrum of the osmoticcontrolled release oral delivery system (OROS), an advanced oral delivery form. Curr Med Res Opin. 2006;22:1879-1892.

28. Boom S, Talluri K, Janssens L, et al. Single- and multiple-dose pharmacokinetics and dose proportionality of the psychotropic agent paliperidone extended release. J Clin Pharmacol. 2009;49:1318-1330.

29. Keith S. Advances in psychotropic formulations. Prog Neuro Psychopharmacol Biol Psychiatry. 2006;30:1879-1892.

30. Rossenu S, Cleton A, Talluri K. Evaluation of the pharmacokinetics of an extended-release formulation of paliperidone with an immediate-release formulation of risperidone. Clin Pharm Ther. 2007;81(Suppl 1):62.

31. Rossenu S, Cleton A, Rusch S, et al. Extended-release formulation of paliperidone shows dose-proportional pharmacokinetics. AAPS J. 2006;8(Suppl):3123.

32. Rossenu S, Crauwels H, Cleton A. Evaluation of the pharmacokinetics of several formulations of paliperidone. AAPS J. 2006;8(Suppl):1042.

33. European_Medicines_Agency. Invega (paliperidone prolonged-release tablets): Summary of product characteristics. Available at: http:// www.emea.europa.eu/humandocs/Humans/EPAR/invega/invega.htm. Accessed February 5, 2011.

34. Ortho-McNeil-Janssen-Pharmaceuticals. Invega (paliperidone) extended-release tablets: US prescribing information. Titusville, NJ: Ortho-McNeil-Janssen-Pharmaceuticals; 2010.

35. Mannens G, Huang M, Meuldermans W, et al. Absorption, metabolism, and excretion of risperidone and its distribution in humans. Drug Metab Dispos. 1993;21:1134-1141.

36. Zhu H, Wang J, Markowitz J, et al. Risperidone and paliperidone inhibit P-glycoprotein activity in vitro. Neuropsychopharmacology. 2007;32:757-764.

37. Berwaerts J, Cleton A, Herben V. The effects of paroxetine on the pharmacokinetics of paliperidone extended-release tablets. Pharmacopsychiatry. 2009;42:158-163.

38. Vermeir M, Naessens I, Remmerie B, et al. Absorption, metabolism, an excretion of paliperidone, a new monoaminergic antagonist, in humans. Drug Metab Dispos. 2008;36:769-779.

39. Boom S, Thyssen A, Crauwels H, et al. The influence of hepatic impairment on the pharmacokinetics of paliperidone. Int J Clin Pharmacol Ther. 2009;47:606-616.

40. Thyssen A, Crauwels H, Cleton A. Effects on renal impairment on the pharmacokinetic profile of paliperidone extended-release. Clin Pharm Ther. 2007;81(Supp1):63.

41. Thyssen A, Cleton A, Talluri K, et al. No pharmacokinetic interaction between paliperidone extended-release tablets and trimethoprim in healthy subjects. Hum Psychopharmacol. 2009;24:532-539.

42. Rossenu S, Cleton A, Boom S, et al. Evaluation of the pharmacokinetics of paliperidone extended-release tablets in healthy elderly subjects. Clin Pharm Ther. 2007;81(Suppl):64.

43. European_Medicines_Agency. Invega (paliperidone prolonged-release tablets): Scientific discussion. Available at: http://www.emea.europa.eu/ huandocs/PDFs/EPAR/invega/H-746-en6.pdf. Accessed February 5, 2011

44. Davidson M, Emsley R, Kramer M, et al. Efficacy, safety and early response of paliperidone extended-release tablets (paliperidone ER): Results of a 6-week, randomized, placebo-controlled study. Schizophr Res. 2007;93:117-130.

45. Kane J, Canas F, Kramer M, et al. Treatment of schizophrenia with paliperidone extended-release tablets: A 6-week placebo-controlled trial. Schizophr Res. 2007;90:147-161.

46. Marder S, Kramer M, Ford L, et al. Efficacy and safety of paliperidone extended-release tablets: Results of a 6-week, randomized, placebocontrolled study. Biol Psychiatry. 2007;62:1363-1370.

47. Kay S, Fiszbein A, Opler L. The positive and negative syndrome scale (PANSS) for schizophrenia. Schizophr Bull. 1987;13: 261-276.
48. Marder S, Davis J, Chouinard G. The effects of risperidone on the five dimensions of schizophrenia derived by factor analysis: Combined results of the North American trials. J Clin Psychiatry. 1997;58:538-546.

49. Guy W. Clinical global impression. In: Guy W, editor. ECDEUAssessment Manual for Psychopharmacology. Rockville, MD: National Institute of Mental Health; 1976.

50. Morosini P, Magliano L, Brambilla L. Development, reliability and acceptability of a new version of the DSM-IV Social and Occupational Functioning Assesment Scale (SODAS) to assess routine social functioning. Acta Psychiatr Scand. 2000;101:323-329.

51. Patrick D, Burns T, Morosini P, et al. Reliability, validity and ability to detect change of the clinician-rated Personal and Social Performance scale in patients with acute symptoms of schizophrenia. Curr Med Res Opin. 2009;25:325-338.

52. Emsley R, Baerwaerts J, Eerdekens M, et al. Efficacy and safety of oral paliperidone extended-release tablets in the treatment of acute schizophrenia: Pooled data from three 52-week open-label studies. Int Clin Psychopharmacol. 2008;23:343-356.

53. Meltzer H, William V, Isaac F, et al. Efficacy and tolerability of oral paliperidone extended-release tablets in the treatment of acute schizophrenia: Pooled data from three 6-week, placebo-controlled studies. J Clin Psychiatry. 2008;69:817-829.

54. Canuso C, Bossie C, Amatniek J, et al. Paliperidone extended-release tablets in patients with recently diagnosed schizophrenia. Early Interv Psych. 2010;4:64-78.

55. Milev P, Ho BC, Arndt S, Andreasen NC. Predictive values of neurocognition and negative symptoms on functional outcome in schizophrenia: A longitudinal first-episode study with 7-year-follow-up. Am J Psychiatry. 2005;162:495-506.

56. Turkoz I, Bossie C, Dirks B, Canuso CM. Direct and indirect effects of paliperidone extended-release tablets on negative symptoms of schizophrenia. Neuropsychiatr Dis Treat. 2008;4:949-958.

57. Canuso C, Turkoz I, Sheehan J, et al. Efficacy and safety of paliperidone extended-release in schizophrenia patients with prominent affective symptoms. J Affect Disord. 2010;120:193-199.

58. Canuso C, Youssef E, Bossie C, et al. Paliperidone extended-release tablets in schizophrenia patients previously treated with risperidone. Int Clin Psychopharmacol. 2008;23:209-215.

59. Tzimos A, Samokhvalov V, Kramer M, et al. Safety and tolerability of oral paliperidone extended-release tablets in elderly patients with schizophrenia. Am J Geriatr Psychiatry. 2008;16:31-43.

60. Wilkinson G, Hesdon B, Wild D, et al. Self-report quality of life measure for people with schizophrenia: The SQLS. Br J Psychiatry. 2000;177:42-46.

61. Kramer M, Simpson G, Maciulis V, et al. Paliperidone extendedrelease tablets for prevention of symptom recurrence in patients with schizophrenia. J Clin Psychopharmacol. 2007;27:6-14.

62. Luthringer R, Staner L, Noel N, et al. A double-blind, placebo-controlled, randomized study evaluating the effect of paliperidone ER tablets on sleep architexture in patients with schizophrenia. Int Clin Psychopharmacol. 2007;22:299-308.

63. Parrott A, Hindmarch I. The Leeds Sleep Evaluation Questionnaire in psychopharmacological investigations: A review. Psychopharmacology (Berl). 1980;71:173-179.

64. Canuso C, Dirks B, Carothers J, et al. Randomized, double-blind, placebo-controlled study of paliperidone extended-release and quetiapine in inpatients with recently exacerbated schizophrenia. $\mathrm{Am}$ J Psychiatry. 2009;166:691-701.

65. Canuso C, Lindenmayer J, Kosik-Gonzalez C, et al. A randomized, double-blind, placebo-controlled study of 2 dose ranges of paliperidone extended-release in the treatment of subjects with schizoaffective disorder. J Clin Psychiatry. 2010;71:587-598.

66. Berwaerts $\mathrm{J}, \mathrm{Xu} \mathrm{H}$, Nuamah I, et al. Evaluation of the efficacy and safety of paliperidone extended-release in the treatment of acute mania: A randomized, double-blind, dose-response study. J Affect Disord. July 10, 2010. [Epub ahead of print]. 
67. Young R, Biggs J, Ziegler V, et al. A rating scale for mania: Reliability, validity and sensitivity. Br J Psychiatry. 1978;133:429-435.

68. Vieta E, Nuamah I, Lim P, et al. A randomized, placebo- and activecontrolled study of paliperidone extended release for the treatment of acute manic and mixed episodes of bipolar I disorder. Bipolar Disord. 2010;12:230-243.

69. Spearing M, Post R, Leverich G, et al. Modification of the Clinical Global Impression (CGI) Scale for use in bipolar illness (BP). Psychiatry Res. 1997;73:159-171.

70. Dremencov E, El Mansari M, Blier P. Distinct electrophysiological effects of paliperidone and risperidone on the firing activity of rat serotonin and norepinephrine neurons. Psychopharmacology (Berl). 2007;194:63-72.

71. Corena-McLeod MP, Oliveros A, Charlesworth C, et al. Paliperidone as a mood stabilizer: A pre-frontal cortex synaptoneurosomal proteomics comparison with lithium and valproic acid after chronic treatment reveals similarities in protein expression. Brain Res. 2008;1233:8-19.

72. Sun F, Su Z, Sui C, et al. Studies on the acute toxicity, pharmacokinetics and pharmacodynamics of paliperidone derivatives - comparison to paliperidone and risperidone in mice and rats. Basic Clin Pharmacol Toxicol. 2010;107:656-662.

73. Knegtering R, Baselmans P, Kastelin C. Predominant role of the 9-hydroxy-metabolite of risperidone in elevating blood prolactin-levels. Am J Psychiatry. 2005;162:1010-1012.

74. Doggal H. Possible malignant neuroleptic syndrome associated with paliperidone. J Neuropsychiatry Clin Neurosci. 2007;19:477-478.

75. Mantas C, Kalabokis G, Goulia P, et al. Possible malignant neuroleptic syndrome during paliperidone administration. J Clin Psychopharmacol. 2010;30:89-91.

76. Hsieh C, Liou Y. Manic symptoms induced by paliperidone. J Clin Psychopharmacol. 2010;30:202-204.

77. Paulzen M, Orphanos S, Gründer G. Remission of drug induced hepatitis after switching from risperidone to paliperidone. Am J Psychiatry. 2010; 167:351-352.
78. Gray R, Rofail D, Allen J, et al. A survey of patient satisfaction with and subjective experiences of treatment with antipsychotic medication. JAdv Nurs. 2005;52:31-37.

79. Mohamed S, Rosenheck R, McEvoy J, et al. Cross-sectional and longitudinal relationships between insight and attitudes toward medication and clinical outcomes in chronic schizophrenia. Schizophr Bull. 2009;35:336-346.

80. Canuso C, Grinspan A, Kalali A, et al. Medication satisfaction in schizophrenia: A blinded-initiation study of paliperidone extended release in patients suboptimally responsive to risperidone. Int Clin Psychopharmacol. 2010;25:155-164.

81. Atkinson M, Sinha A, Hass S, et al. Validation of a general measure of treatment satisfaction, the treatment satisfaction questionnaire for medication (TSQM), using a national panel study of chronic diseases. Health Qual Life Outcomes. 2004;2:12.

82. Kalali A. Evaluating patient satisfaction: A practical approach. Clear Perspectives. 1999;2:18-21.

83. Sokal J, Messias E, Dickerson F, et al. Comorbidity of medical illness among adults with serious mental illness who are receiving community psychiatric services. J Nerv Ment Dis. 2004;192:421-427.

84. Geitona M, Kousoulakou H, Ollandezoss M, et al. Costs and effects of paliperidone extended release compared with alternative oral antipsychotic agents in patients with schizophrenia in Greece: A cost effectiveness study. Ann Gen Psychiatry. 2008;7:16.

85. Edwards N, Pesa J, Meletiche D. One-year clinical and economic consequences of oral typical antipsychotics in the treatment of schizophrenia. Curr Med Res Opin. 2008;24:3341-3355.

86. Berto P, Negrini C, Ferrannini L. Analisi costo-efficacia di paliperidone ER nel trattamento delle ricadute della schizofrenia, nella prospettiva del Sistema Sanitario Nazionale italiano. Farmeconomia e Percorsi Terapeutici. 2008;9:95-108.
Drug Design, Development and Therapy

\section{Publish your work in this journal}

Drug Design, Development and Therapy is an international, peerreviewed open-access journal that spans the spectrum of drug design and development through to clinical applications. Clinical outcomes, patient safety, and programs for the development and effective, safe, and sustained use of medicines are a feature of the journal, which

\section{Dovepress}

has also been accepted for indexing on PubMed Central. The manuscript management system is completely online and includes a very quick and fair peer-review system, which is all easy to use. Visit $\mathrm{http}: / /$ www.dovepress.com/testimonials.php to read real quotes from published authors. 